\title{
The effective stiffness of modern unreinforced masonry walls
}

\author{
Bastian Valentin Wilding ${ }^{1}$ \\ bastian.wilding@epfl.ch
}

Katrin Beyer ${ }^{1}$ - corresponding author

katrin.beyer@epfl.ch

${ }^{1}$ Earthquake Engineering and Structural Dynamics Laboratory (EESD), School of Architecture, Civil and Environmental Engineering (ENAC), École Polytechnique Fédérale de Lausanne (EPFL), EPFL ENAC IIC EESD, GC B2 504, Station 18, 1015 Lausanne, Switzerland

\begin{abstract}
Code design of unreinforced masonry (URM) buildings is based on elastic analysis, which requires as input parameter the effective stiffness of URM walls. Eurocode estimates the effective stiffness as $50 \%$ of the gross sectional elastic stiffness but comparisons with experimental results have shown that this may not yield accurate predictions. In this paper, 79 shear-compression tests of modern URM walls of different masonry typologies from the literature are investigated. It shows that both the initial and the effective stiffness increase with increasing axial load ratio and that the effective-to-initial stiffness ratios are approximately $75 \%$ rather than the stipulated $50 \%$. An empirical relationship that estimates the E-modulus as a function of the axial load and the masonry compressive strength is proposed, yielding better estimates of the elastic modulus than the provision in Eurocode 6, which calculates the E-modulus as a multiple of the compressive strength. For computing the ratio of the effective to initial stiffness, a mechanics-based formulation is built on a recently developed analytical model for the force-displacement response of URM walls. The model attributes the loss in stiffness to diagonal cracking and brick crushing, both of which are taken into account using mechanical considerations. The obtained results of the effective-to-initial stiffness ratio agree well with the test data. A sensitivity analysis using the validated model shows that the ratio of effective-to-initial stiffness is for most axial load ratios and wall geometries around $75 \%$. Therefore, a modification of the fixed ratio of effective-to-initial stiffness from $50 \%$ to $75 \%$ is suggested.
\end{abstract}

Keywords: unreinforced masonry walls; effective stiffness; shear controlled; flexure controlled

\section{$1 \quad$ Introduction}

Seismic design of structures can be conducted using two different concepts: force-based and displacement-based design [1]. In the former, the base shear force for which the structure needs to be designed depends on the mass and the first or several natural frequencies of the structure. To account for the effect of cracking, the dynamic properties of the structures are computed on the basis of effective stiffness rather than gross stiffness values. Furthermore, the stiffness of the individual components is important for the force distribution within the structure: The global force applied on a system is distributed between the system's load bearing components according to their respective effective stiffnesses.

Displacement-based procedures are mainly used for the assessment of existing structures, e.g. [2,3]. Besides the strength they also consider the deformation capacity of the components [4,5], which is typically defined for an unreinforced masonry (URM) wall as a certain ultimate drift capacity where drift is the horizontal displacement divided by the interstorey height, assumed in here to be equal to the wall height. For the assessment of URM walls, the non-linear force-displacement behaviour can be approximated by means of a bi-linear curve [6], Figure 1a. One input parameter for the construction of these curves is, again, the effective stiffness $\left(k_{e f}\right)$. With the exception of procedures that make use of the substitute structure approach [5,7], which use the secant stiffness at ultimate displacement, the effective stiffness is an important structural property in both force-based and displacement-based assessment methods of URM structures. 
(a)

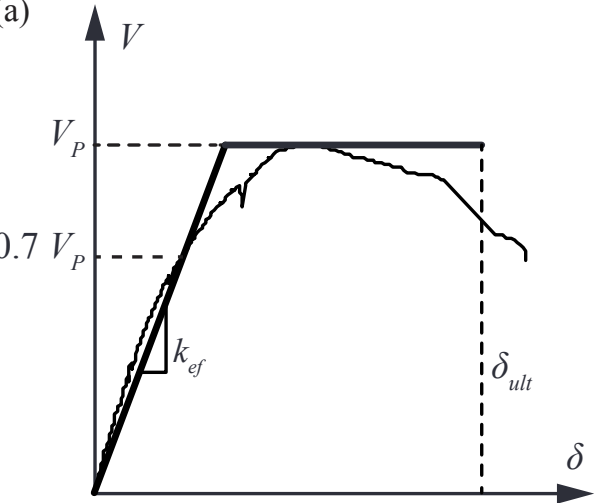

(b)

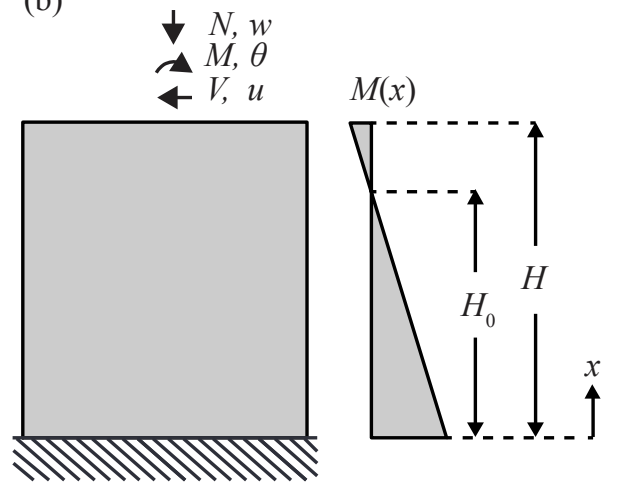

Figure 1: (a) Monotonic shear force-drift response of an URM wall test in Petry \& Beyer [8] and bi-linear approximation with indication of effective stiffness $\left(k_{e f}\right)$, peak shear capacity $\left(V_{P}\right)$ and ultimate drift capacity $\left(\delta_{u l t}\right)$, drift is defined as the horizontal displacement by the wall height. (b) Wall with moment profile along with forces and corresponding degrees of freedom on top (normal force $N$ and axial displacement $w$, moment $M$ and rotation $\theta$, shear force $V$ and horizontal displacement $u$ ).

A frequently used approach for modelling URM buildings is the so-called equivalent frame method, e.g. [9,10]. This term describes a simplified modelling approach in which walls and spandrels are represented by beam- or macro-elements that are connected by rigid nodes. In order to compute the shear force-displacement curve of the equivalent frame subjected to a horizontal load, the behaviour of its constituents, i.e., walls and spandrels, have to be known. For the analysis of URM buildings, beam- and macro-elements have been developed to be used in the equivalent frame method [11-16]. In several of these models, walls and spandrels are approximated by Timoshenko beams. The elastic stiffness of a Timoshenko beam with a linear moment profile can be obtained according to Eq. (1) where $H$ is the wall height, $H_{0}$ the shear span (Figure 1b), $E$ the elastic modulus of masonry, $I$ the gross sectional moment of inertia, $\kappa$ the shear coefficient, $G$ the shear modulus of masonry and $A$ the gross sectional area. The factors $f_{1}$ and $f_{2}$ are the stiffness reduction factors for the flexural and the shear component, respectively.

$$
k_{e f}=\left(\frac{H^{2}\left(H_{0}-\frac{H}{3}\right)}{f_{1} 2 E I}+\frac{\kappa H}{f_{2} G A}\right)^{-1}
$$

According to Eurocode 8 (EC8) Part 1 [17], the effective stiffness should account for the influence of cracking. In the absence of more accurate information, EC8 suggests that the effective stiffness be estimated as half the gross sectional stiffness. Therefore the stiffness reduction factors $f_{1}$ and $f_{2}$ are both set to 0.5 . Such an approach assumes that the effect of cracking equally affects walls developing a shear controlled and walls showing a flexure controlled behaviour. The behaviour-type depends on the material parameters, the wall geometry, along with the static and kinematic boundary conditions. In a hyperstatic system, approximating the effective stiffness as a fixed percentage of the gross sectional stiffness means that the forces are effectively distributed proportional to the gross sectional stiffness. According to e.g. [18,19], the effective stiffness is dependent on the axial load, which is not taken into account by the current EC8 approach.

When determining the effective stiffness from experimental results of shear-compression tests, it is typically defined as the secant stiffness of the wall at $70 \%$ of its peak shear capacity, e.g. [6,16]. For stone masonry walls it is found that in average the effective stiffness corresponds to $50 \%$ of their elastic stiffness [18], as proposed by EC8, albeit with a coefficient of variation $(\mathrm{CoV})$ of around $50 \%$. Contrastingly, a comparison to full-scale tests on modern URM walls in Sect. 2 shows that EC8 may significantly underestimate the effective stiffness of modern URM walls.

The objective of this article is to investigate which parameters influence the initial and effective stiffness of modern URM walls. The term modern URM walls is used in this article for walls made with masonry units in accordance to EN 771-1 to 4 [20-23] and mortars according to EN 1996-2 [24] and EN 998-2 [25] respectively. This encompasses walls made with clay, calcium silicate as well as (aerated or aggregate) concrete units with general purpose or thin layer mortar. Experimental evidence from the data of 79 full-scale shear-compression tests of inplane loaded modern URM walls, compiled for this study, is presented and trends of the initial and the ratio of effective to initial stiffness are investigated in Sect. 2. A mechanics-based method for estimating the effective stiffness of URM walls, which explicitly considers the influence of cracking on the effective stiffness by means of analytical formulations that are based on a model by Wilding \& Beyer [26] is introduced in Sect. 3 and validated in Sect. 4. Subsequently, in Sect. 5, a parametric study is conducted using the analytical model to investigate the 
influence of static and kinematic boundary conditions on the ratio of effective to initial stiffness before formulating recommendations for effective stiffness estimates in future code generations (Sect. 6).

\section{Experimental evidence}

The presented data stems from experimental campaigns of large-scale shear-compression tests of modern URM walls. The following masonry typologies are considered: walls made with clay, calcium silicate and aerated concrete units and both thin and normal-thickness bed-joints (Table 1). The selection criteria for the experimental campaigns are: (i) wall height $\geq 1.5 \mathrm{~m}$, wall length $\geq 1.0 \mathrm{~m}$; (ii) constant shear span during test; (iii) constant axial load during test, and (iv) availability of the force-displacement history. The considered results are obtained from ten campaigns [8,19,27-34] and comprise 79 specimens (Table 2). The main parameters of each test are summarized in Table 8 in Appendix A.

\subsection{Data base}

Figure 2 presents an overview of the test data by plotting the shear span ratio vs the axial load ratio (Figure 2a, b, c) and the ratio of wall-to-brick height vs the ratio of wall-to-brick length (Figure $2 \mathrm{~d}$, e). Furthermore, shear and flexural failure (Figure 2a), masonry typologies (Figure 2b, d) and experimental campaigns (Figure 2c, e) are distinguished. Generally, the considered data set covers a rather wide range of shear spans and axial load ratios. Figure $2 \mathrm{a}$ shows that the shear span ratio and the axial load ratio are rather good predictors of the failure mode; the higher the shear span ratio and the lower the axial load ratio, the more likely it is that the wall fails in flexure rather than in shear. However, there appears to be a domain in which both modes of failure may happen; this applies for shear span ratios of approximately one with a low to moderate axial load ratio. The presented failure modes correspond to the ones reported in the reference documents. If the behaviour was reported as 'hybrid' or 'doubtful', it was assigned to flexure or shear based on the shape of the final cycles of the shear force-drift hysteresis.

Table 1: Masonry typologies

\begin{tabular}{cclc}
\hline No. & Abbreviation & \multicolumn{1}{c}{ Typology } & No. of walls \\
\hline 1 & CL/PE/NO & Vertically perforated clay units with normal thickness bed-joints & 44 \\
2 & CL/PE/TH & Vertically perforated clay units with thin bed-joints & 4 \\
3 & CL/FU/NO & Solid clay units with normal thickness bed-joints & 5 \\
4 & $\mathrm{CS} / \mathrm{FU} / \mathrm{NO}$ & Solid calcium-silicate units with normal thickness bed-joints & 10 \\
5 & $\mathrm{CS} / \mathrm{FU} / \mathrm{TH}$ & Solid calcium-silicate units with thin bed-joints & 12 \\
6 & $\mathrm{AC} / \mathrm{FU}$ & Solid aerated concrete units & 4 \\
\hline
\end{tabular}

Table 2: Considered experimental campaigns

\begin{tabular}{ccccc}
\hline No. & Reference & No. of walls & Typology & Test type \\
\hline 1 & Petry \& Beyer [8] & 6 & CL/PE/NO & Cyclic \\
2 & Bosiljkov et al. [29] & 6 & CL/PE/NO & Cyclic \\
3 & Ganz \& Thürlimann [27] & 4 & CL/PE/NO & Mono, Cyclic \\
4 & Salmanpour et al. [19] & 9 & CL/PE/NO, CS/FU/NO & Cyclic \\
5 & Bosiljkov et al. [28] & 14 & $\mathrm{CL} / \mathrm{PE} / \mathrm{NO}$ & Cyclic \\
6 & Graziotti et al. [30] & 2 & $\mathrm{CS} / \mathrm{FU} / \mathrm{NO}$ & Cyclic \\
7 & Graziotti et al. [31] & 5 & $\mathrm{CL} / \mathrm{FU} / \mathrm{NO}$ & Cyclic \\
8 & Messali et al. [32] & 6 & $\mathrm{CS} / \mathrm{FU} / \mathrm{NO}$ & Cyclic \\
9 & Magenes et al. [33] & 17 & $\mathrm{CL} / \mathrm{PE} / \mathrm{NO}, \mathrm{CL} / \mathrm{PE} / \mathrm{TH}, \mathrm{CS} / \mathrm{FU} / \mathrm{TH}$ & Cyclic \\
10 & Ötes \& Löring [34] & 10 & $\mathrm{CL} / \mathrm{PE} / \mathrm{NO}, \mathrm{CS} / \mathrm{FU} / \mathrm{TH}, \mathrm{AC} / \mathrm{FU}$ & Cyclic \\
\hline
\end{tabular}

Figure $2 \mathrm{~b}$ shows that while the CL/PE/NO tests cover a wide range of axial load and shear span ratios, experiments of CS/FU/NO walls are limited to roughly one axial load ratio but were conducted for various shear span ratios. The wall characteristics in terms of wall-to-unit size are illustrated in Figure $2 d$ and e. Figure $2 d$ shows that the wall-to-unit size of the CL/PE/NO walls is representative of modern unit sizes with approximately six to twelve 
brick courses over the wall height. By contrast, three campaigns on walls with full bricks (CL/FU/NO and $\mathrm{CS} / \mathrm{FU} / \mathrm{NO}$ ) were constructed using bricks of 50-70 $\mathrm{mm}$ height, which leads to a significantly larger wall-to-unit height ratios of up to 55 brick courses per wall. Most walls comprise 5-10 bricks per course but Figure 2e shows that some were built with as few as two and a half bricks per course. When the size of the bricks is of a similar order as the size of the wall, employing a Timoshenko beam element model for computing the wall stiffness, as employed in this study, might be questionable. However, in engineering practice, such wall geometries are likely to be rare.

(a)

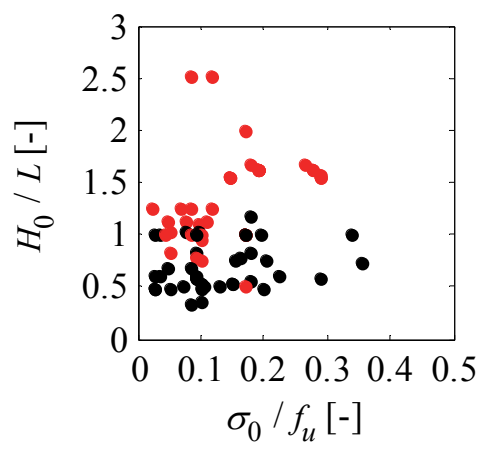

(a):

- Shear

- Flexure

$$
\text { (c) \& (e): }
$$

- Messali et al. (2017)

- Graziotti et al. (2016a)

- Graziotti et al. (2016b)

- Petry \& Beyer (2015)

(b) \& (d):

- Salmanpour et al. (2015)

^ CL/PE/NO - Magenes et al. (2008)

- $\mathrm{AC} / \mathrm{FU}$

- Ötes \& Löring (2008)

- CL/FU/NO - Bosiljkov et al. (2006)
$\Delta \mathrm{CL} / \mathrm{PE} / \mathrm{TH}$

$\Delta \mathrm{CS} / \mathrm{FU} / \mathrm{NO}$ Bosiljkov et al. (2004)

^ CS/FU/TH Ganz \& Thürlimann (1984) (b)

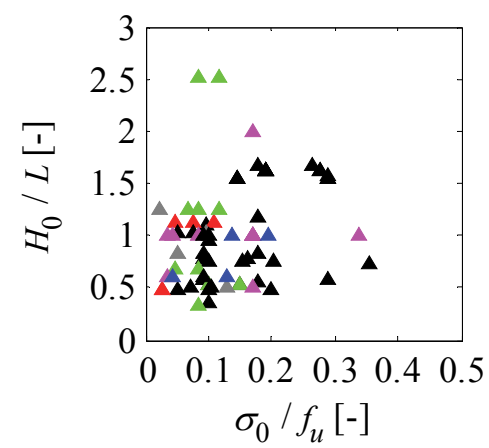

(d)

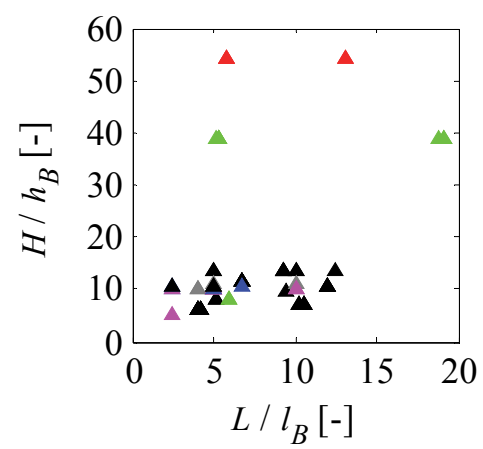

(c)

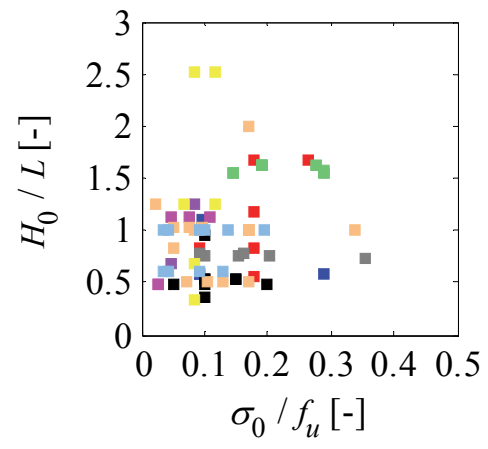

(e)

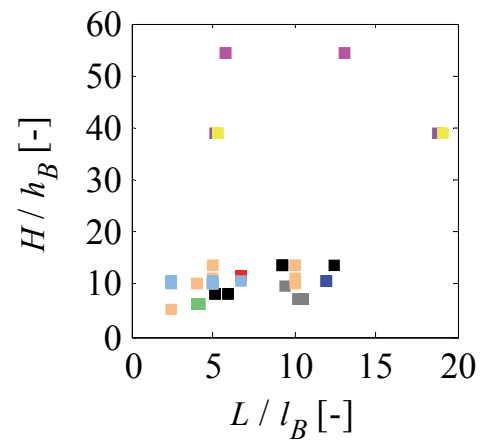

Figure 2: Wall database: Distribution of test specimens with regard to several parameters: shear span ratio vs axial load ratio with walls separated by (a) failure mode, (b) masonry typology, (c) experimental campaign; wall to brick height vs wall to brick length with walls separated by (d) masonry typology, (e) experimental campaign

\subsection{Stiffness}

In the following, two measures of stiffness are used: the effective and the initial in-plane stiffness of the wall. The effective stiffness $k_{e f}$ is computed as the secant stiffness of the shear force-displacement envelope at first attainment of $70 \%$ of the peak shear capacity (mean of both loading directions), while the initial stiffness $k_{\text {init }}$ represents the mean of the initial stiffnesses of the envelope shear-force displacement responses in the two loading directions.

\subsubsection{Initial stiffness}

The elastic modulus per wall is determined by back-calculating it from the initial stiffness $k_{\text {init }}$ using Timoshenko beam theory [see Eq. (2), the procedure of determining $k_{\text {init }}$ is further outlined in Appendix B]. It is assumed that the shear modulus is one fourth of the elastic modulus of masonry $(G=1 / 4 E)$ as suggested in [35] as there appears to be scientific evidence that the current estimate in Eurocode 6 Part 1 [36] and ASCE 41 [37] (referring to TMS 402 [38]) to take $40 \%$ of the elastic modulus is too high for structural elements in masonry, e.g. [39]. Tomaževič [39] even suggests a $G / E$ ratio as low as 0.1 based on a limited number of shear-compression and small-scale compression tests, back-calculated using Timoshenko beam theory. Furthermore, the American masonry code TMS 402 [38] states that there is no experimental evidence supporting a $G / E$ ratio of 0.4 but that is simply a historically given value.

$$
E_{\text {init }}=k_{\text {init }}\left[\frac{H^{2}\left(H_{0}-\frac{H}{3}\right)}{2 I}+\frac{4 \kappa H}{A}\right]
$$


Figure 3 a shows the ratio of back-calculated elastic moduli $E_{\text {init }}$ to masonry compressive strength $f_{u}$ vs the axial load ratio. There appears to be a general upward trend for the elastic modulus with increasing axial load, which is in line with observations in Vanin et al. [18] for historical stone masonry walls. Derakhshan et al. [40] even report an increase in out-of-plane stiffness of URM walls subjected to one-way bending with increasing axial load. Yet many codes simply estimate the E-modulus as a multiple of the compressive masonry strength $f_{u}$, e.g. $E=1000 f_{u, k}$ as suggested in Eurocode 6 (EC6) Part 1 [36]. Since all values in this article are on the mean statistical level whereas the provision according to EC6 applies to the characteristic one (i.e. the $5 \%$ quantile of a certain normal distribution), it is reformulated as $E=900 f_{u}$ corresponding to a normal distribution with a coefficient of variance $(\mathrm{CoV})$ of $6 \%$, which agrees with the reported $\mathrm{CoV}$ of the masonry compression tests in [8,19,31] (if no information on the probability distribution were known EN 1052-1 [41] proposes the mean strength to be 20\% larger than the characteristic one, corresponding to $E=833 f_{u}$ ). The modified relation is included in Figure 3 a as dashed line. Estimating the stiffness as fixed multiple of the compression strength however appears not to be in line with the observed trend and leads to errors when estimating the effective stiffness.

Considering the experimental results, two linear regressions of the elastic modulus based on the axial load may be proposed for practical applications, see Figure $3 \mathrm{~b}$ and c. It is distinguished between walls with clay bricks and calcium-silicate bricks; for aerated concrete bricks the data base is insufficient. Besides the raw data, a moving average (blue line), a linear regression curve of the data (green and back line respectively), the Pearson correlation coefficient $(r)$ and the p-value $(p)$ are provided in Figure $3 \mathrm{~b}$ and c. The correlation coefficient is a measure of how well the data corresponds to the linear regression curve; so the higher $r$, the better the linear correlation represents the actual data. The $p$-value is a measure of the strength of the evidence against a null hypothesis; the smaller the $p$-value, the stronger the evidence against said null hypothesis [42]. The null hypothesis in this article is: there is no correlation between the chosen indicators. A commonly used significance level is $p<0.05[42,43]$. For both types of bricks, the $p$-value suggests that there is a correlation between the ratio of $E / f_{u}$ and the axial load ratio $\sigma_{0} / f_{u}$. The linear regression curves read as ( $\sigma_{0}$ is the axial stress on the wall):

$$
\frac{E\left(\sigma_{0}\right)}{f_{u}}=\left\{\begin{array}{l}
473+1870 \frac{\sigma_{0}}{f_{u}} \text { for clay brick masonry walls } \\
713+3119 \frac{\sigma_{0}}{f_{u}} \text { for calcium silicate brick masonry walls }
\end{array}\right.
$$

For design purposes, these equations can be approximated as:

$$
E\left(\sigma_{0}\right)=\alpha f_{u}\left(1+\beta \frac{\sigma_{0}}{f_{u}}\right)
$$

where $\alpha=470$ for clay brick and $\alpha=720$ for calcium silicate brick masonry walls while $\beta=4$ for both types.

(a)

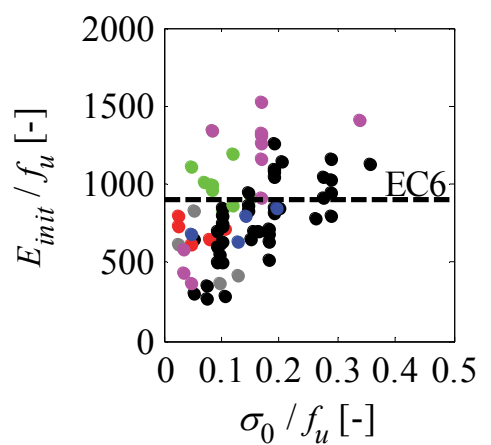

(b)

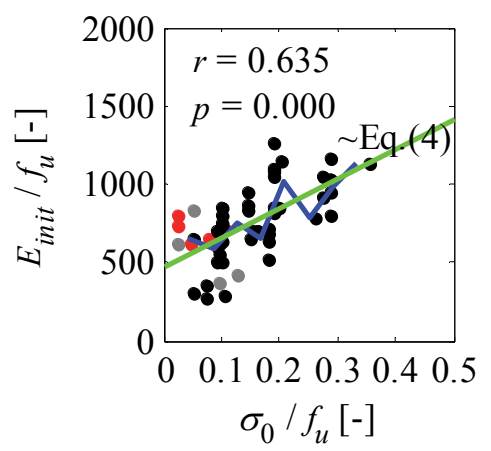

(c)

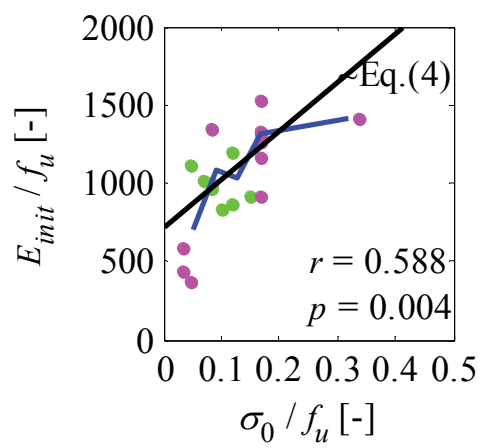

Figure 3: (a) Elastic moduli back-calculated from test results, (b) back-calculated elastic moduli of clay brick walls, (c) back-calculated elastic moduli of calcium silicate brick walls vs axial load ratio

In Figure 4a, the empirical relation proposed in Eq. (4), and the approach according to EC6 are compared in predicting the actual elastic modulus $E_{\text {init }}$ based on the measured initial stiffness. 
(a)

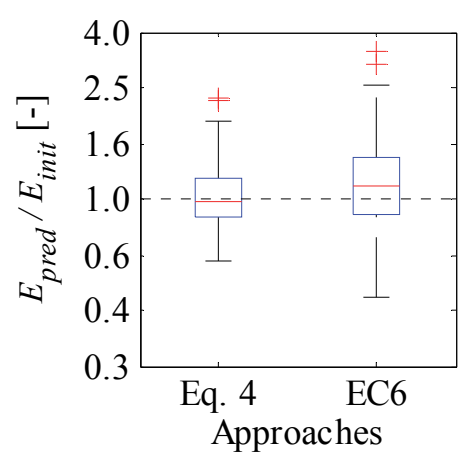

(b)

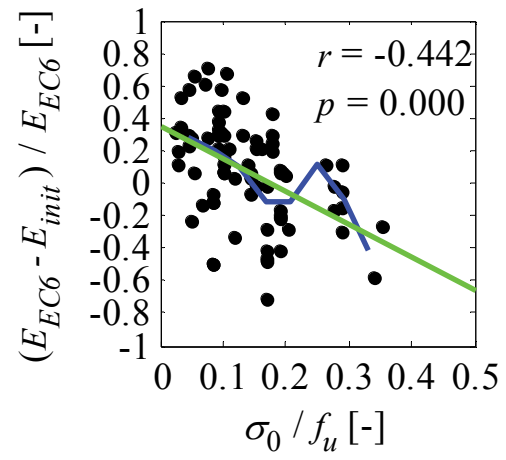

(c)

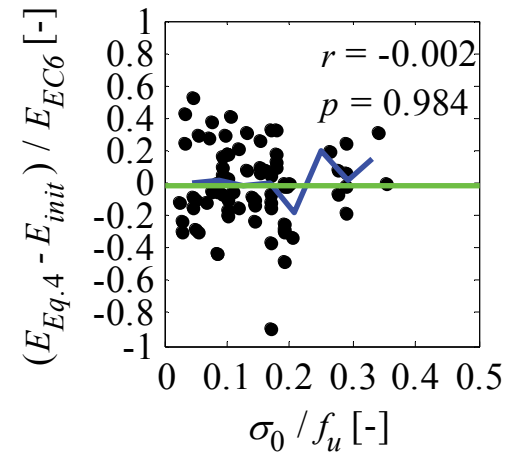

Figure 4: (a) Boxplot of performance of approaches of predicting elastic modulus, (b) normalized residuals for approach acc. to EC6, (c) normalized residuals for proposed approach acc. to Eq. (4)

Equation (4), which expresses the elastic modulus as a function of $f_{u}$ and $\sigma_{0} / f_{u}$, largely removes the bias with regard to $\sigma_{0} / f_{u}$ and predicts the elastic modulus more accurately than the approach in EC6 and may therefore be considered in practical applications where only few wall parameters are known and no force-displacement curves from similar tests are available. Figure $4 \mathrm{~b}$ and $\mathrm{c}$ show the normalized residuals against the axial load ratio for the approach according to EC6 and the proposed formulation. The goodness of the predictions by EC6 changes significantly with the axial load ratio, while the residuals for Eq. (4) do not depend on it.

In order to determine the elastic modulus experimentally, EN 1052-1 [41] demands a tangent modulus from axial compression tests of small-scale URM specimens to be retrieved. Consequently, the proposed EC6-formulation is possibly fitted from said small-scale tests. However, these are the only provisions there are. Therefore an engineer has to use this formulation also for predictions of the in-plane force-displacement of full-scale URM shear walls. In order to improve the situation with regard to the latter kind of structural element, the difference between measured data and code provision is highlighted while at the same an alternative is proposed.

Throughout this article it is assumed that $G / E=0.25$; the initial elastic moduli presented in this section are backcalculated from the initial stiffness considering Timoshenko beam theory and the assumption of $G / E=0.25$ influences the value of said elastic moduli. If the hypothesis of $G / E=0.40$ (acc. to EC6 [36]) were used, the initial elastic moduli would reduce and the factors $\alpha$ and $\beta$ in the proposed Eq. (4) would change to $\alpha=340$ (clay units) and 550 (calcium-silicate units) respectively with $\beta=5$. It should be stressed, however, that this assumption does not have a significant influence on the general trends presented in this section and has none at all on the stiffness ratios presented in Sect. 2.2.2. Furthermore it has neither a significant impact on the model presented in Sect. 3, nor its validation in Sect. 4, nor the parametric studies in Sect. 5.

\subsubsection{Effective to initial stiffness}

An overview of the effective-to-initial stiffness ratio in the dataset is provided in Figure 5. Figure 5a distinguishes between flexure and shear controlled walls. Independently of the failure mode, the effective stiffness of nearly all walls lies above the estimate according to EC8 Part 1 [17], which suggests the effective stiffness be approximated as $50 \%$ of the elastic stiffness (dashed line). The test results suggest however that the effective stiffness corresponds in average to around $70-75 \%$ of the initial stiffness. Furthermore it appears that flexure controlled walls show a slightly larger dispersion around the mean than shear controlled ones. Figure $5 \mathrm{~b}$ suggests that there is no significant difference concerning the mean value of the effective-to-initial stiffness between the considered masonry typologies. Table 3 sums up the above-mentioned and provides the mean and the coefficient of variation $(\mathrm{CoV})$ for the effective-to-initial stiffness ratio per failure mode and masonry typology, respectively. It is chosen in the following to propose an effective-to-initial stiffness ratio 0.75 as the typology for which the largest amount of tests were analysed (perforated clay brick walls, $\mathrm{CL} / \mathrm{PE} / \mathrm{NO}$ ) shows this ratio. The other typologies are represented by significantly fewer tests, which furthermore seem to contain some outliers (especially for calciumsilicate walls) reducing the value of effective to initial stiffness, see especially typologies 4 and 5 in Figure $5 \mathrm{~b}$. 
(a)

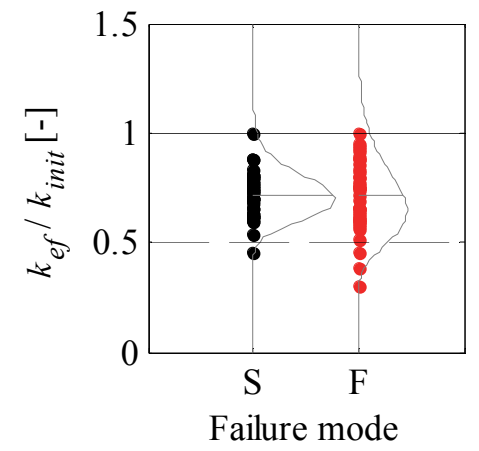

(b)

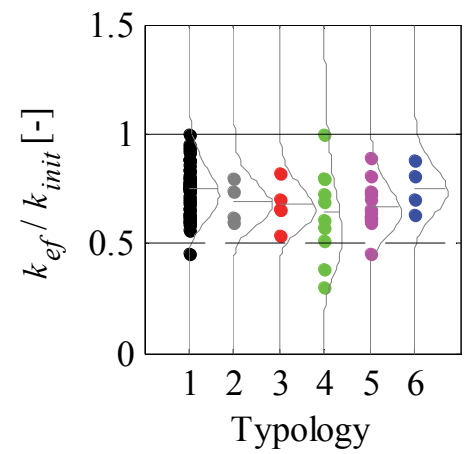

Figure 5: Effective-to-initial stiffness ratio vs (a) failure mode, (b) wall typology; including corresponding lognormal probability distribution functions and indications of mean

Table 3: Summary of effective-to-elastic stiffness ratio per failure mode and masonry typology

\begin{tabular}{ccccc}
\hline Short & Indicator & mean $\left(k_{\text {ef }} / k_{\text {init }}\right)$ & $\operatorname{CoV}\left(k_{\text {ef }} / k_{\text {init }}\right)$ & No. of walls \\
\hline $\mathrm{S}$ & Failure mode & & 41 \\
$\mathrm{~F}$ & Shear & 0.72 & 0.14 & 38 \\
\hline & Flexure & 0.71 & 0.23 & 44 \\
2 & & Typology & 4 \\
3 & $\mathrm{CL} / \mathrm{PE} / \mathrm{NO}$ & 0.75 & 0.16 & 5 \\
4 & $\mathrm{CL} / \mathrm{PE} / \mathrm{TH}$ & 0.69 & $-1)$ & 10 \\
\hline & $\mathrm{CL} / \mathrm{FU} / \mathrm{NO}$ & 0.68 & $-1)$ & 12 \\
\hline
\end{tabular}

1) For sample sizes smaller than 10 , the $\mathrm{CoV}$ was not computed.

\section{All tests}

The effective-to-initial stiffness ratio $k_{e f} / k_{\text {init }}$ vs the axial load ratio is presented in Figure 6a. It appears to be relatively constant with the axial load ratio, which indicates that both the effective and the initial stiffness depend on the applied axial loading, which was already indicated previously in e.g. [18,19]. Besides the raw data, a moving average (blue line) and a linear regression curve of the data (green line) is shown. Furthermore, the correlation coefficient $(r)$ and the p-value $(p)$ are provided. Figure $6 \mathrm{~b}$ plots the same stiffness measure vs the shear span ratio (shear span $H_{0}$ by wall length $L$ ). The p-value indicates that there appears to be no significant trend between them.

(a)

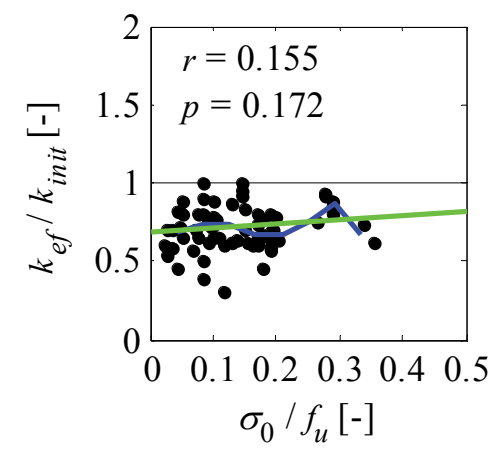

(b)

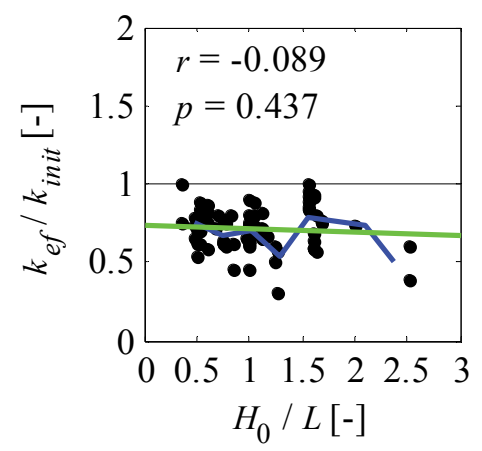

Figure 6: Experimental results: effective-to-initial stiffness vs (a) axial load ratio, (b) shear span ratio 


\section{By failure mode}

Figure 7 presents the effective-to-initial stiffness ratio over the axial load ratio, this time separating the tests by failure mode. Figure $7 \mathrm{~b}$ and $\mathrm{c}$ indicate that there appears to be a significantly stronger increase in the effective stiffness with the axial load ratio for flexure controlled walls than for shear controlled walls.

(a)

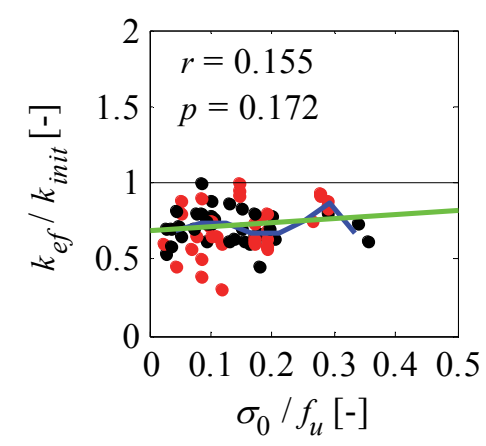

(d)

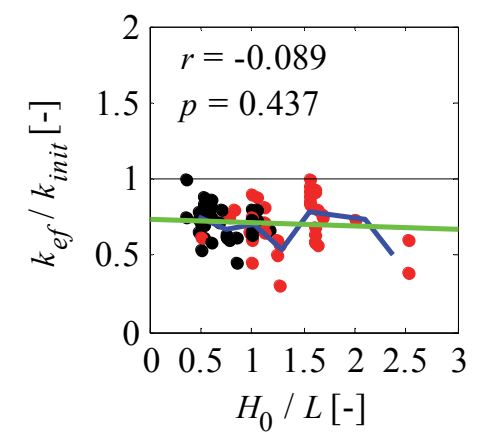

(b)

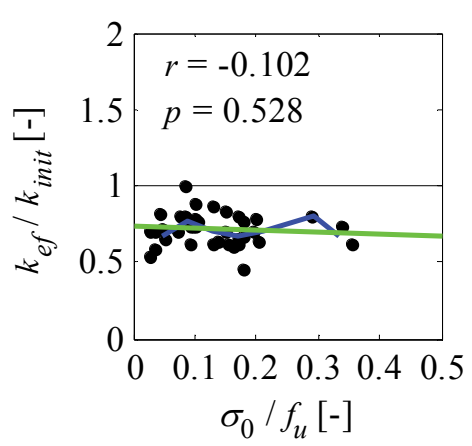

(e)

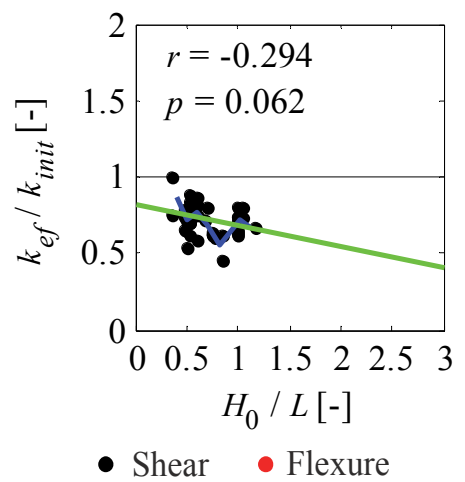

(c)

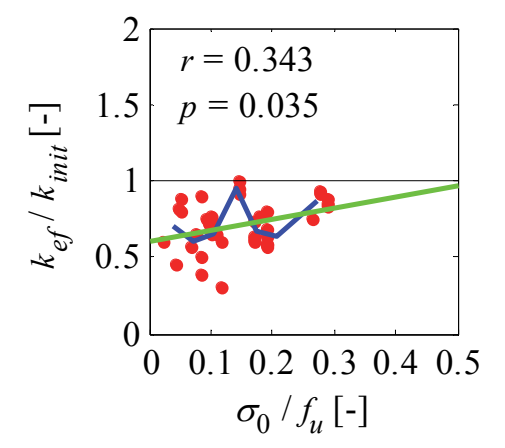

(f)

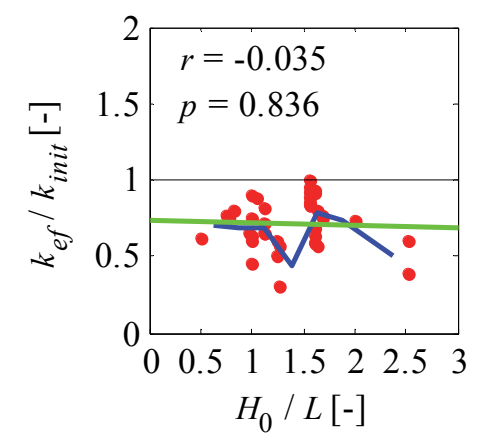

Figure 7: Experimental results: effective-to-initial stiffness vs axial load ratio (a) all walls, (b) walls failing in shear, (c) walls failing in flexure; effective-to-initial stiffness vs shear span ratio (d) all walls, (e) walls failing in shear, (f) walls failing in flexure

Generally, the decrease in stiffness (from initial to effective) may be attributed to two distinct cracking mechanisms: Diagonal shear cracking, prevalent in shear controlled walls, and flexural cracking or uplift of the bed-joints due to partial decompression of a cross section, which is the governing cracking mechanism in flexure controlled walls. The reason for why the effective stiffness in flexure controlled walls changes significantly more strongly with the axial load may be that the extent of flexural cracking is more dependent on the axial load than diagonal cracking. This seems to be indicated by the mechanics-based model introduced in Sect. 3.3.

If only the shear controlled walls are considered, the effective stiffness seems to decrease with increasing shear span ratio, Figure 7e. This trend, however, vanishes for flexure controlled walls (Figure 7f). An explanation for this might be that as the shear span ratio gets higher, the failure mode will gradually change from shear to flexure (see also Figure 2). Shear controlled walls with a relatively high shear span ratio may experience a significant amount of diagonal and flexural cracking both of which lead to a softening of the wall stiffness. In flexure controlled walls, however, only flexural cracking takes place notwithstanding the shear span ratio.

\section{By masonry typology}

In this section, the data is separated by masonry typology, Figure 8. No difference in terms of dependency of the effective-to-initial stiffness ratio on the axial load ratio can be observed (Figure 8b, c). Similar can be said concerning the effective-to-initial stiffness vs the shear span ratio plots, see Figure 8e, f. There appears to be one weak downward trend in effective-to-initial stiffness for all typologies but vertically perforated clay unit walls with normal thickness bed-joints (CL/PE/NO). It might, however, well be that this possible dependency only appears due to a limited number of wall tests. 
(a)

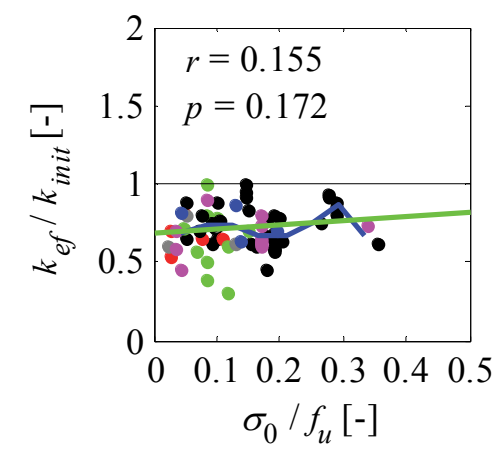

(d)

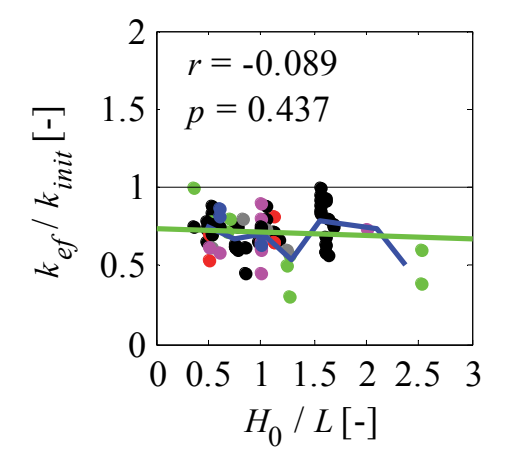

(b)

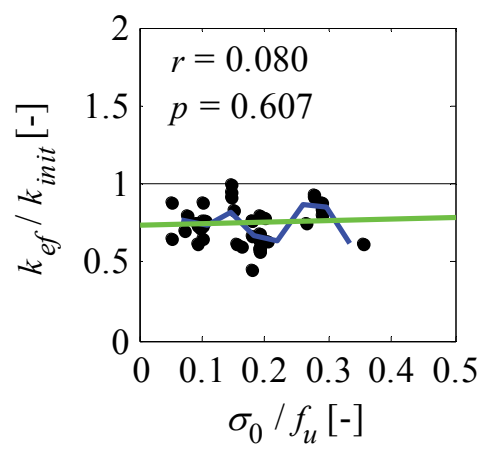

(e)

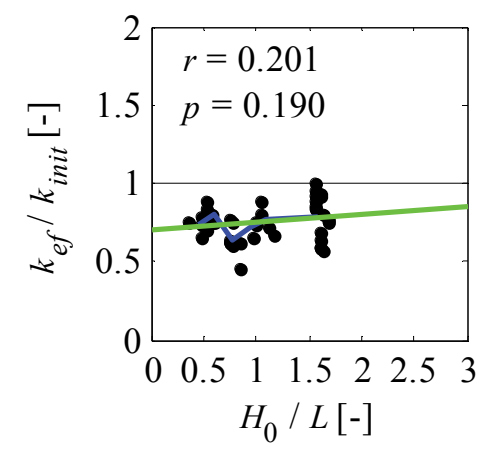

(c)

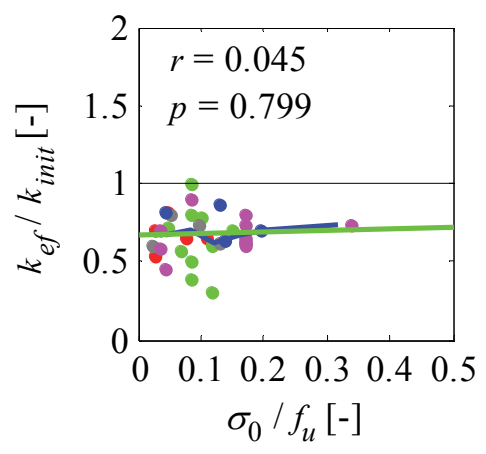

(f)

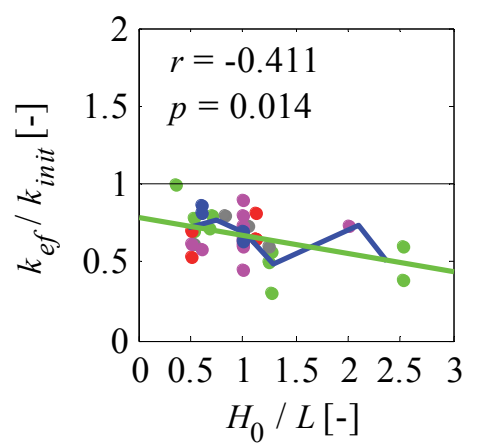

\section{$\bullet \mathrm{CL} / \mathrm{PE} / \mathrm{NO} \bullet \mathrm{AC} / \mathrm{FU} \bullet \mathrm{CL} / \mathrm{FU} / \mathrm{NO} \cdot \mathrm{CL} / \mathrm{PE} / \mathrm{TH} \cdot \mathrm{CS} / \mathrm{FU} / \mathrm{NO} \bullet \mathrm{CS} / \mathrm{FU} / \mathrm{TH}$}

Figure 8: Results of selected test campaigns by typology; effective-to-initial stiffness vs axial load ratio (a) all walls, (b) vertically perforated clay units and bed joints of normal thickness, (c) other typologies; effective-toinitial stiffness vs shear span ratio (d) all walls, (e) vertically perforated clay units and bed joints of normal thickness, (f) other typologies

\subsubsection{Summary of findings}

The main findings of this section can be summarized as follows:

- There appears to be an upward trend for the effective and the initial stiffness with increasing axial load ratio.

- $\quad$ For the initial stiffness, this increase in stiffness with increasing axial load ratio can be accounted for by expressing the E-modulus as a function of the axial load ratio [see Eq. (4)]. The effective stiffness can be interpreted as this initial stiffness times the ratio of effective-to-initial stiffness.

- The experimental results indicate that this effective-to-initial stiffness ratio is only slightly dependent on the axial load ratio, the shear span ratio and the behaviour mode of the wall (shear vs flexure).

- For flexure controlled walls, the effective-to-initial stiffness ratio appears to increase with increasing axial load ratio, while for shear controlled walls the effective-to-initial stiffness ratio seems rather independent of this measure.

- The effective-to-initial stiffness ratio seems to decrease with increasing shear span ratio in shear controlled walls while there appears to be no such trend in flexure controlled ones.

To investigate the dependency of the effective-to-initial stiffness ratio on the wall geometry, static and kinematic boundary conditions, a model is put forward in the next section, which allows for an analytical derivation of this ratio.

\section{An analytical model for the effective-to-initial stiffness ratio}

A simplified method accounting for the influence of the flexural cracking of bed joints and diagonal shear cracking based on the more complex Critical Diagonal Crack (CDC) model [26] is outlined in the following. To determine whether a wall develops shear or flexural cracks or both, an approach to distinguish between shear controlled walls (diagonal shear cracking) and flexure controlled walls (rocking with flexural cracking of bed-joints) is required. 
Therefore, first, two different approaches are presented that may be used to differentiate shear and flexure controlled walls.

\subsection{Determining the failure mode}

\subsubsection{Eurocode 8}

EC8 Part 3 [44] determines the behaviour type of a URM wall by comparing the shear capacity of the wall for shear and flexural failure. The capacity associated with shear failure is described by a Mohr-Coulomb criterion and the flexural capacity is based on a compressive failure at the wall toe. The smaller value of the two controls the failure mode. Advantages of this approach are the mechanical background and its simplicity. However, to determine the effective stiffness, EC8 neglects any effect of the behaviour type on the ratio of effective-to-initial stiffness and simply assigns half the gross sectional stiffness independently of the wall behaviour.

\subsubsection{Shear span ratio}

A simple approach to distinguish between shear and flexure controlled walls is to use the shear span ratio $H_{0} / L$ since Figure 2a in Sect. 2.1 indicates that it nearly always permits a correct classification of the behaviour type. It is assumed that walls with a shear span ratio of one and larger develop a flexure controlled behaviour while walls with a shear span ratio smaller than one are shear controlled.

\subsubsection{Comparison of methods}

A comparison of the above-presented approaches to predict the wall behaviour-type is shown in Figure 9. First (Figure 9a) the ratio of correct predictions by the considered approaches per behaviour-type as observed in the tests for all masonry typologies are presented. While the provisions according to Eurocode 8 part 3 [44] are right in $61 / 79$ cases, the shear span ratio fares similarly well and assigns the correct prediction to 63/79. The shear span ratio fares better in predicting shear controlled walls with the approach in EC8 being slightly superior for the prediction of flexure controlled ones. Only walls of the CL/PE/NO typology are considered in Figure 9b as they represent the biggest sample in the dataset with, as it appears, the lowest uncertainty. Furthermore the original CDC model, on which the model introduced in the following is based, has been validated with this typology. Both approaches show again similar agreement: 37/44 for EC8 and 38/44 using the shear span ratio. Concluding, it can be said that despite its simplicity, the shear span ratio proves to be a good indicator of the wall behaviour-type with an even slightly better performance than the approach in EC8.

(a)

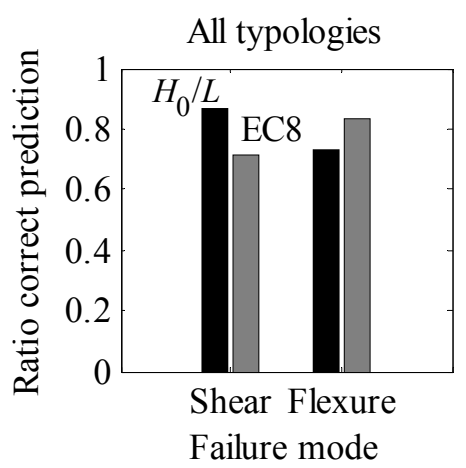

(b)

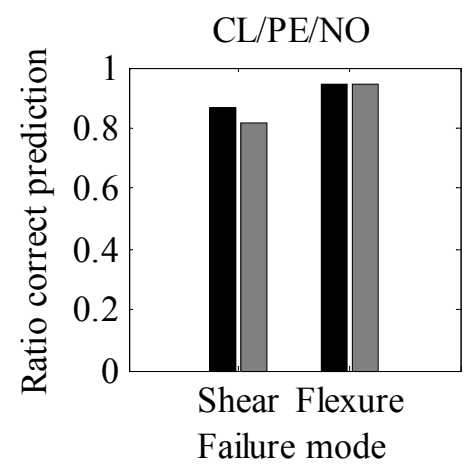

Figure 9: Comparison of prediction performance of failure mode, (a) Eurocode 8 [44] and shear span ratio, all tests; (b) Eurocode 8 [44] and shear span ratio, only CL/PE/NO typology. Black indicates predictions using the shear span ratio and grey the ones according to EC8.

\subsection{Gamma approach}

The gamma approach was introduced in [26] and permits to distinguish implicitly between controlled by shear or flexure by introducing a factor $\gamma$, which is dependent on an indicator and zero for shear while one for flexure controlled walls. The factor $\gamma$ is suggested herein as a function of the shear span ratio and can be computed as given by Eq. (5). It allows for considering both flexural and diagonal shear cracking when computing the effective stiffness, as will be shown in Sect. 3.3 and Eq. (21). 


$$
\gamma= \begin{cases}0 & \text { for } \frac{H_{0}}{L}<0.5 \\ 2\left(-\frac{1}{2}+\frac{H_{0}}{L}\right) & \text { for } 0.5 \leq \frac{H_{0}}{L} \leq 1 \\ 1 & \text { for } \frac{H_{0}}{L}>1\end{cases}
$$

\subsection{Modelling the effective-to-initial stiffness ratio}

In this section, a simplified approach to explicitly derive the stiffness reduction factors for the flexural and the shear displacement component, to be used in Eq. (1), is presented. The method is based on the CDC model as introduced in [26] and attempts to approximate the curvature and shear strain profiles from the CDC model at 70\% of the peak shear capacity by means of simplified interpolation functions. In the CDC model, it is assumed that flexural horizontal cracking in the bed-joints can be captured by reducing the respective cross section length. Furthermore diagonal shear cracking is captured by a further reduction of the length of cross sections that are crossed by said diagonal crack. Therefore all reduction in stiffness is attributed to a decrease in cross sectional values, i.e., the moment of inertia $(I)$ and the area of the cross section $(A)$. The material stiffness parameters $E$ and $G$ (elastic and shear modulus) are kept constant, i.e. the material is assumed to be linear-elastic in compression and shear; the tensile strength of the masonry is neglected. In the CDC model, the values of the moment of inertia and the cross sectional area vary over the height of the wall. For the simplified model presented here, average values are computed, which lead to the same top displacement for cross sectional values that are constant over the wall height. As a consequence, the stiffness reduction factors related to flexural $\left(f_{1}\right)$ and shear $\left(f_{2}\right)$ component of the horizontal displacement [see also Eq. (1)] can be written as the ratio of average-reduced to gross sectional values:

$$
f_{1}=\frac{I_{\text {avg }}}{I}, \quad f_{2}=\frac{A_{\text {avg }}}{A}
$$

\subsubsection{Reduction of flexural stiffness}

To obtain the average-reduced moment of inertia, the horizontal flexural top displacements $\left(u_{f, t o p}\right)$ for the double integral of the 'real' curvature profile $[\chi(x)]$ and the curvature profile obtained with a constant moment of inertia over the wall height $\left[M(x) / E I_{\text {avg }}\right]$ have to be equal.

$$
u_{f l, t o p}=\iint_{0}^{H} \frac{M(x)}{E I_{\text {avg }}} d x=\iint_{0}^{H} \chi(x) d x
$$

Where $M(x)$ is the moment profile at the height $x$. Integrating the linear moment profile $M(x)$ and solving the resulting expression for $I_{\text {avg }}$ yields:

$$
I_{\text {avg }}=\frac{V H^{2}\left(H_{0}-\frac{H}{3}\right)}{2 E \iint_{0}^{H} \chi(x) d x}
$$

The shear force $V$ is, in accordance to the definition of the effective stiffness, $70 \%$ of the shear capacity of the wall $\left(V=0.7 V_{P}\right)$. Dividing Eq. (8) by the gross moment of inertia yields an expression for the flexural stiffness reduction factor $f_{1}$ based on a curvature profile $\chi(x)$ that still needs to be determined.

$$
f_{1}=\frac{I_{\text {avg }}}{I}=\frac{6 V H^{2}\left(H_{0}-\frac{H}{3}\right)}{L^{3} T E \iint_{0}^{H} \chi(x) d x}=\frac{6 V H^{2}\left(H_{0}-\frac{H}{3}\right)}{L^{3} T E u_{f l, t o p}}
$$

Where $T$ is the wall thickness. For flexure controlled walls, an approximation of the required curvature profile with an exponential function is proposed based on the curvature at the wall base $\chi_{b}$ and a constant $c$.

$$
\chi(x)=\chi_{b} e^{c x}
$$

The constant $c$ can be obtained analytically by evaluating the curvature $\chi_{2}$ of a wall cross section at wall height $\mathrm{H}_{2}$, where $H_{2} \neq H_{0}$ for mathematical stability. Good estimates for $H_{2}$ appear to be situated between $H / 2$ and $H / 3$. 


$$
c=\ln \left(\frac{\chi_{2}}{\chi_{b}}\right) \frac{1}{H_{2}}
$$

The curvature of a cross section undergoing flexural decompression can be obtained using Eq. (12) [26,35]. The two curvatures $\chi_{b}$ and $\chi_{2}$ can therefore be obtained by setting $x$ to 0 and $H_{2}$ respectively.

$$
\chi(x)=\frac{2 N}{E L_{c}^{2}(x) T}
$$

Where $N$ is the normal force on the wall. The compressed length $L_{c}(x)$ of a cross section undergoing only flexural decompression but no shear cracking (flexure controlled walls) can be determined as follows $[26,35,45]$.

$$
L_{c}(x)=3\left(\frac{L}{2}-\frac{V\left(H_{0}-x\right)}{N}\right)
$$

Integrating Eq. (10) twice along the wall height yields an equation for the flexural displacement at the wall top for flexure controlled walls.

$$
u_{f l, t o p}=\iint_{0}^{H} \chi(x) d x=\frac{\chi_{b}}{c^{2}}\left[e^{c H}-c H-1\right]
$$

For shear controlled walls, the curvature profile is assumed to follow a linear function that is dependent on the base curvature $\chi_{b}$ and the shear span $H_{0}$.

$$
\chi(x)=\chi_{b}\left(1-\frac{x}{H_{0}}\right)
$$

The double integral of Eq. (15) over the wall height leads to an equation for the flexural top displacement for shear controlled walls.

$$
u_{f l, t o p}=\iint_{0}^{H} \chi(x) d x=\chi_{b} \frac{H^{2}}{2}\left(1-\frac{H}{3 H_{0}}\right)
$$

For shear controlled walls that undergo diagonal shear cracking, the influence of said mechanism is considered by introducing an average reduction factor $r_{\text {avg. }}$. This factor reduces the gross sectional moment of inertia and therefore the base curvature $\chi_{b}$ increases:

$$
\chi_{b}=\frac{M(x=0)}{E I r_{a v g}}=\frac{12 V H_{0}}{E L^{3} T r_{a v g}}
$$

Corresponding to the assumptions in [26], diagonal cracking in the pre-peak regime at $0.7 V_{P}(70 \%$ of the peak shear capacity) is supposed to expand over the whole wall apart from the first and last course of bricks respectively due to the confinement effect of the rather stiff foundation and ceiling slabs (see Figure 10c). Figure 10a shows the resulting assumed linearized profile of reduced-to-full moment of inertia $\left(I_{s c}(x) / I\right)$ based in a diagonal crack separating two wall halves (and therefore splitting the subjected cross sections in two) as illustrated in Figure 10c. The said factor $r_{\text {avg }}$ represents therefore the average ratio of reduced to gross sectional moment of inertia. The formulation below can be used, evaluating two sections and assuming a linear distribution of the moment of inertia in-between due to diagonal cracking.

$$
r_{\text {avg }}=\frac{2 h_{B} r_{1}+\left(r_{2}+r_{3}\right)\left(\frac{H}{2}-h_{B}\right)}{H}
$$

Where $h_{B}$ is the height of a brick. The ratios of reduced to gross sectional moment of inertia $\left(r_{2}, r_{3}\right)$ in Eq. (18) can be obtained according to the following relations, with $r_{1}=1$.

$$
\begin{aligned}
& r_{2}=\frac{\left(L-l_{B}\right)^{3}+l_{B}^{3}}{L^{3}} \\
& r_{3}=\frac{2(0.5 L)^{3}}{L^{3}}=\frac{1}{4}
\end{aligned}
$$

Examples of curvature, rotation and displacement profiles of a shear and a flexure controlled wall comparing the measured profiles (tests by [8], specimens PUP1 and PUP3, see also Table 8 in Appendix A), the ones according to the $\mathrm{CDC}$ model and the approximated ones (CDCs) following the above-introduced interpolation functions [Eqs. (14) and (16)] are shown in Figure 10b and c. A good agreement can be observed. 
(a) $I_{s c}(x) / I$ :

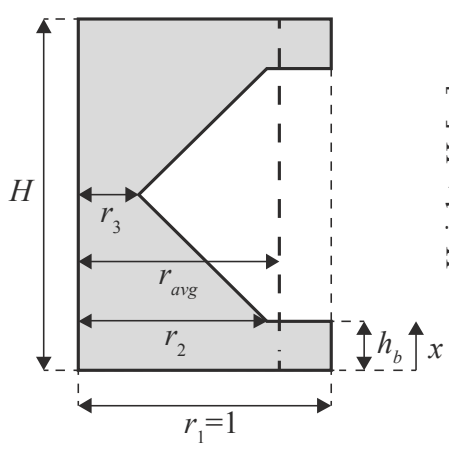

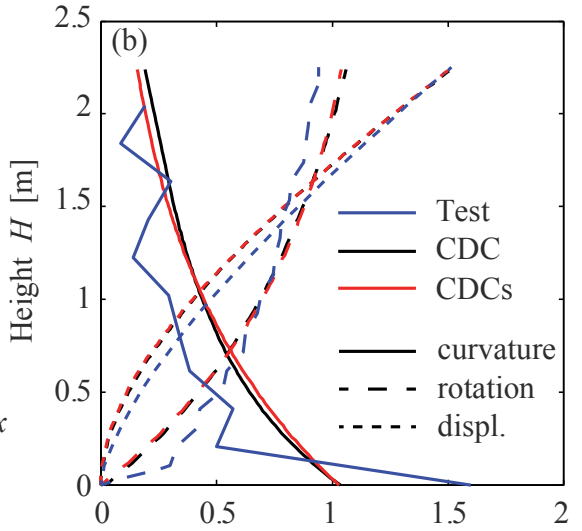

Curvature [1/m], Rotation [rad], Displacement [m]

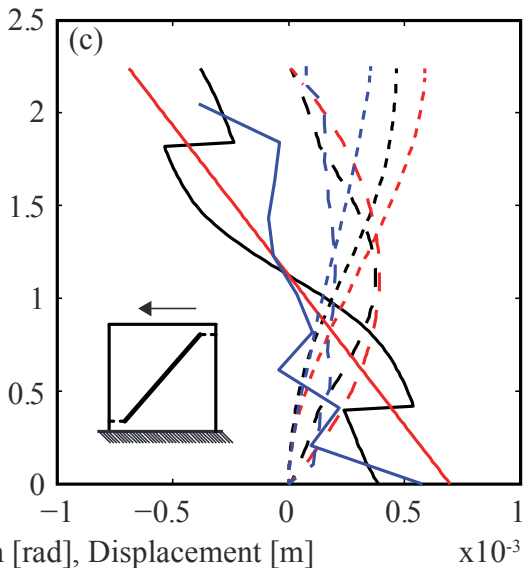

Figure 10: (a) assumed profile of reduced to gross sectional moment of inertia along the wall height; curvature, rotation and displacement profiles including test results by [8] (specimens PUP1 and PUP3) for (b) flexure controlled wall with shear span of $1.5 \mathrm{H}$ and (c) shear controlled wall with shear span of $0.5 \mathrm{H}$

Employing the gamma approach as introduced in Sect. 3.2, the flexural component of the horizontal top displacement can be determined by a linear combination of Eqs. (14) and (16) for all wall-behaviour types. Observe the different notation for the base curvatures: $\chi_{b, f c}$ for flexure controlled and $\chi_{b, s c}$ for shear controlled walls, since they are determined differently [see Eqs. (12) and (17)].

$$
u_{f l, t o p}=\gamma \frac{\chi_{b, f c}}{c^{2}}\left[e^{c H}-c H-1\right]+(1-\gamma) \chi_{b, s c} \frac{H^{2}}{2}\left(1-\frac{H}{3 H_{0}}\right)
$$

\subsubsection{Reduction of shear stiffness}

The reduction of the shear stiffness can be expressed by considering an average-reduced compressed length along the wall height, which is based on the compressed length of the base section $\left[L_{c}(x=0)\right]$ and the height along which decompression occurs $\left(h_{d}\right)$, see Figure 11a.
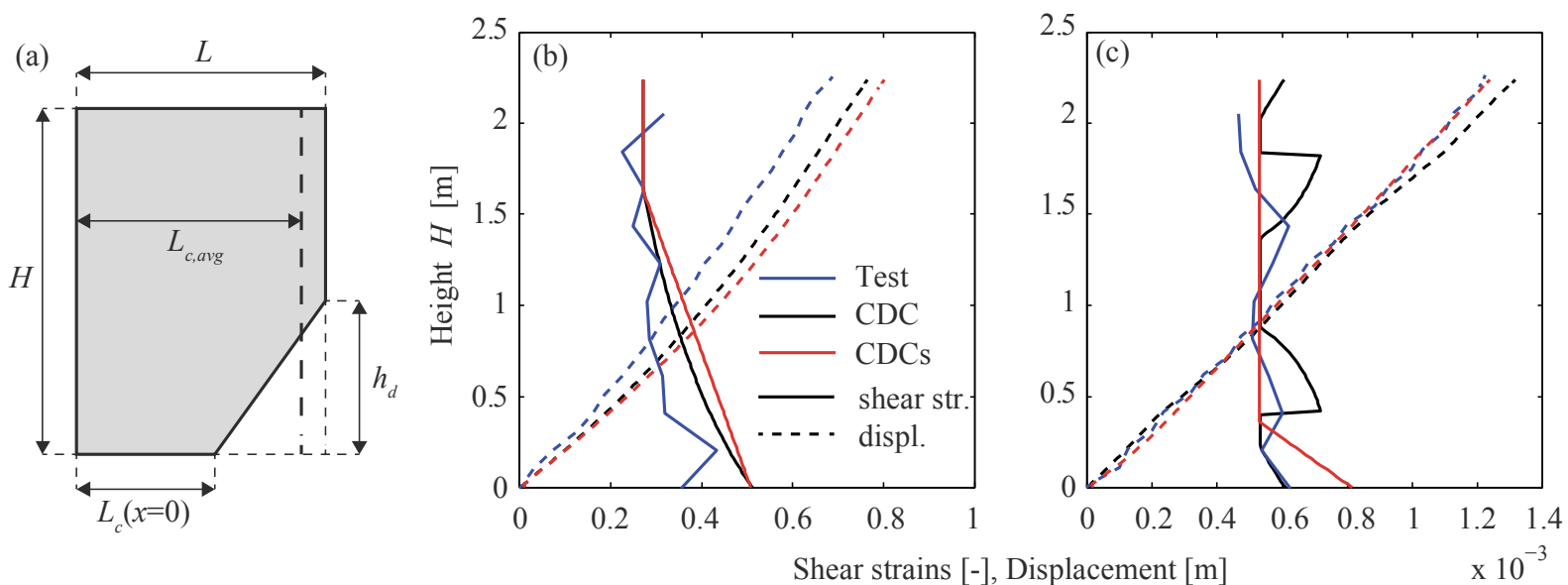

Figure 11: (a) wall undergoing flexural decompression at the base, compressed area in grey; shear strain and displacement profiles including test results by [8] (specimens PUP1 and PUP3) for (b) flexure controlled wall with shear span of $1.5 \mathrm{H}$ and (c) shear controlled wall with shear span of $0.5 \mathrm{H}$

$$
L_{c, a v g}=L-\frac{L-L_{c}(x=0)}{H} \frac{h_{d}}{2}
$$

The decompressed height $h_{d}$ can be determined following the formulation introduced in e.g. [26]. The wall length is reduced by up to one brick length $\left(l_{B}\right)$ to account for the influence of diagonal shear cracking depending on the wall behaviour-type.

$$
h_{d}=H_{0}-\frac{N\left[L-l_{B}(1-\gamma)\right]}{6 V}
$$

The compressed length at the base section is determined corresponding to Eq. (13), this time explicitly accounting for the wall behaviour-type similar to Eq. (23). 


$$
L_{c}(x=0)=3\left(\frac{L-l_{B}(1-\gamma)}{2}-\frac{V H_{0}}{N}\right)
$$

The stiffness reduction factor for the shear component of the horizontal displacement can therefore be obtained using the following relation:

$$
f_{2}=\frac{A_{a v g}}{A}=\frac{L_{c, a v g}}{L}=1-\frac{L-L_{c}(x=0)}{L H} \frac{h_{d}}{2}
$$

Figure $11 \mathrm{~b}$ and $\mathrm{c}$ compare the shear strain and resulting shear displacement profiles of the above-introduced simplified formulation and the more complex CDC model. For both flexure and shear controlled walls, a rather good agreement can be achieved between measured profiles by [8], the CDC model [26] and its simplification.

\section{Comparison and validation}

The data set of full-scale shear-compression tests introduced in Sect. 2 is used for comparing the performance of the above-discussed methods in predicting the effective stiffness. The compared approaches are: (i) the original CDC model [26]; (ii) the proposed simplified version of the CDC model; (iii) the provision of EC8 Part 1 [17]; (iv) a modification of the approach according to EC 8 , reducing the initial stiffness only by $25 \%$ instead of the proposed $50 \%$. In line with previous sections a $G / E$ ratio of 0.25 is assumed for all approaches. Figure 12 illustrates the comparison by means of scatter and boxplots. The corresponding statistics are summarized in Table 4 .

(a)

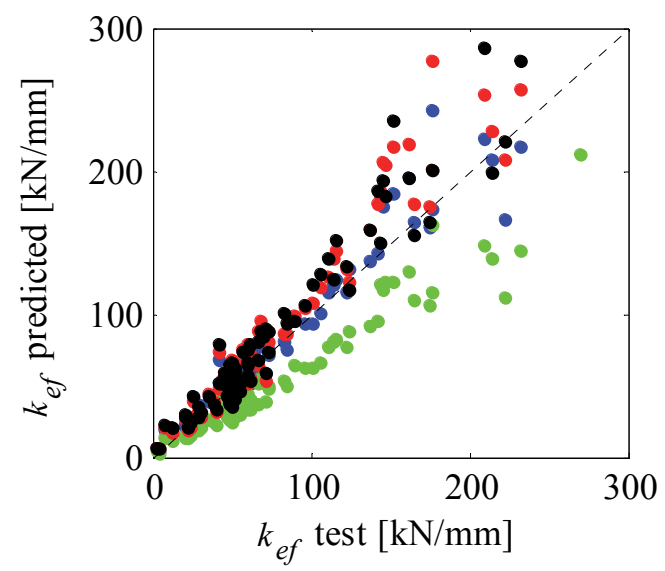

(c)

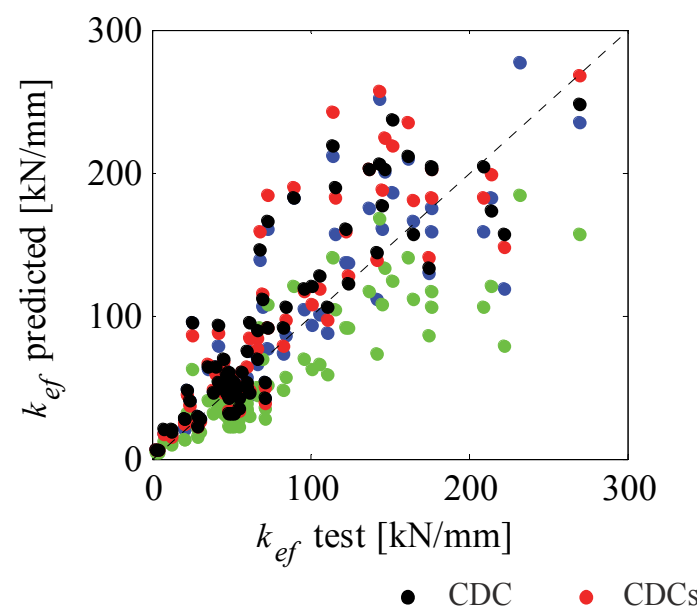

(b)

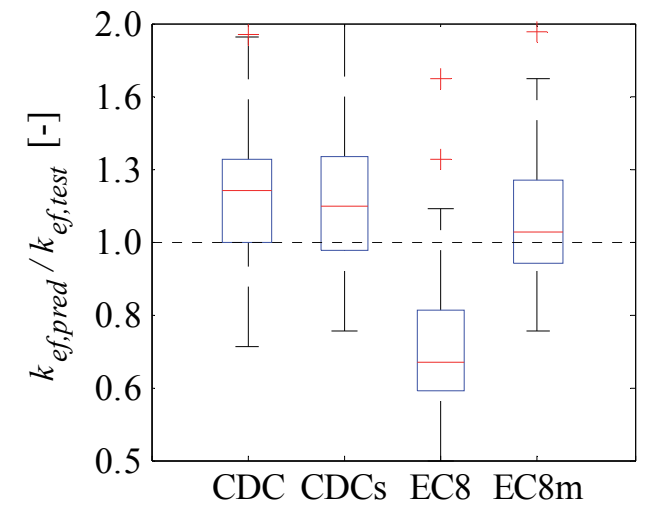

(d)

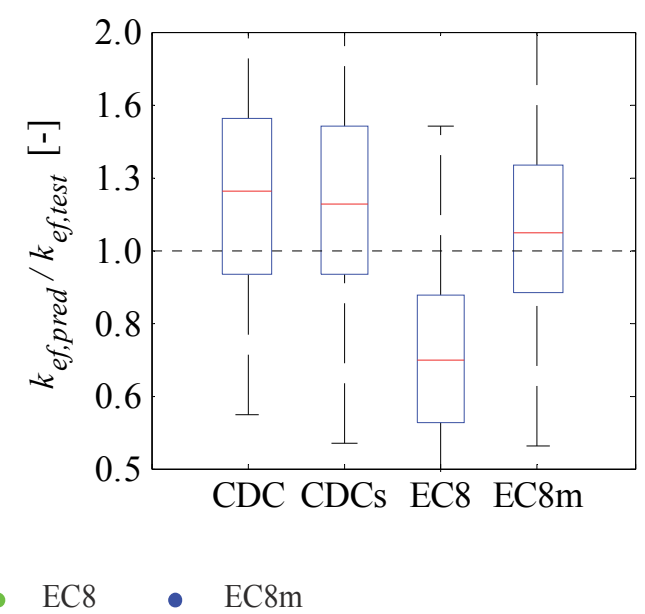

Figure 12: Using measured initial stiffness as input (a) predicted vs measured effective stiffness, (b) corresponding boxplot; using proposed formulation of $E$ (c) predicted vs measured effective stiffness, (d) corresponding boxplot

Figure $12 \mathrm{a}$ and $\mathrm{b}$ present the comparison using the actual measured values of the initial stiffness as input parameter for all the models, while Figure 12c and d do so using the initial stiffness calculated according to the empirical relation proposed in Eq. (4). Consequently, the scatter is significantly higher for the latter case since the error 
stems from both the estimation of the initial and the effective stiffness and not only from an error in the ratio of the effective-to-initial stiffness ratio as in the former case. Figure 12 shows that the largest part of the scatter results from uncertainties related to the initial stiffness and therefore not from errors in determining the effective-to-initial stiffness ratio.

The EC8-approach underestimates the actual effective stiffness by quite a large margin. The other three approaches however lead to nearly the same result and therefore also to a very similar fit in predicting the effective stiffness of the tests. Apparently, using a constant reduction factor of 0.75 performs slightly better than the more complex models (CDC, simplified CDC) despite not accounting for an influence of axial loading on the effective-to-initial stiffness ratio. The good fit of this simple approach might be related to the following two factors. First, the reduction of the elastic stiffness by $25 \%\left(f_{1}=f_{2}=0.75\right)$ is validated against the same data set from which the ratio was derived. The more complex and general formulations CDC and simplified CDC perform equally well without fitting and even predict the average reduction factor of 0.75 rather well, as will be shown in the following section. Second, the correlations between effective stiffness and wall geometry as well as effective stiffness and shear span are considered by all the present approaches as all methods are based on Timoshenko-beam models.

Table 4: Performance of considered models for estimating the effective stiffness

\begin{tabular}{ccccccccc}
\hline \multirow{2}{*}{$k_{\text {ef,pred }} / k_{\text {ef,test }}$} & \multicolumn{2}{c}{ Mean } & \multicolumn{2}{c}{ Median } & \multicolumn{2}{c}{ Std. } & \multicolumn{2}{c}{ CoV } \\
& $E_{\text {init }}$ & $E\left(\sigma_{0} / f_{u}\right)$ & $E_{\text {init }}$ & $E\left(\sigma_{0} / f_{u}\right)$ & $E_{\text {init }}$ & $E\left(\sigma_{0} / f_{u}\right)$ & $E_{\text {init }}$ & $E\left(\sigma_{0} / f_{u}\right)$ \\
\hline CDC & 1.19 & 1.28 & 1.17 & 1.21 & 0.32 & 0.51 & 0.27 & 0.40 \\
CDC simplified & 1.17 & 1.25 & 1.12 & 1.16 & 0.28 & 0.50 & 0.24 & 0.40 \\
EC8 $\left(f_{1}=f_{2}=0.5\right)$ & 0.73 & 0.79 & 0.69 & 0.70 & 0.18 & 0.33 & 0.24 & 0.42 \\
EC8 mod. $\left(f_{1}=f_{2}=0.75\right)$ & 1.10 & 1.18 & 1.03 & 1.06 & 0.26 & 0.49 & 0.24 & 0.42 \\
\hline
\end{tabular}

To reinforce that a change in $G / E$ ratio does not have a significant influence on the performance of the presented model, Table 5 compares the statistics from Table 4 for the option $E_{\text {init }}$ to the ones using a $G / E$ ratio of 0.4 . As can be seen, the difference in results is negligibly small. The assumption of a $G / E$ ratio has only a very limited effect on the proposed formulation for the reduction factor $f_{1}$. The elastic modulus enters in the denominator and the numerator which cancels its influence mostly out [see Eqs. (9) and (14) in Sect. 3.3.1]. Moreover, no material parameter is used in the equation for $f_{2}$ [Eq. (25) in Sect. 3.3.2]. Furthermore the elastic and shear moduli used in the validation are back-calculated form the same initial stiffness measurements simply using different values for $G / E$ so the resulting initial stiffness has to be, again, the same notwithstanding the assumption of $G / E$.

Table 5: Performance of considered models for estimating the effective stiffness, comparison $G / E=0.25$ vs 0.40

\begin{tabular}{cccccccccc}
\hline$k_{\text {ef,pred }} / k_{\text {ef,test }}$ & \multicolumn{2}{c}{ Mean } & \multicolumn{2}{c}{ Median } & \multicolumn{2}{c}{ Std. } & \multicolumn{3}{c}{ CoV } \\
$G / E$ & 0.25 & 0.40 & 0.25 & 0.40 & 0.25 & 0.40 & 0.25 & 0.40 \\
\hline CDC & 1.19 & 1.18 & 1.17 & 1.15 & 0.32 & 0.32 & 0.27 & 0.27 \\
CDC simplified & 1.17 & 1.13 & 1.12 & 1.08 & 0.28 & 0.27 & 0.24 & 0.24 \\
EC8 $\left(f_{1}=f_{2}=0.5\right)$ & 0.73 & 0.73 & 0.69 & 0.69 & 0.18 & 0.18 & 0.24 & 0.24 \\
EC8 $\bmod .\left(f_{1}=f_{2}=0.75\right)$ & 1.10 & 1.09 & 1.03 & 1.03 & 0.26 & 0.26 & 0.24 & 0.24 \\
\hline
\end{tabular}

The stiffness reduction factors as predicted explicitly by the simplified CDC model for the considered tests are presented graphically in Figure 13 including the respective lognormal probability distribution functions with indications of the mean. There is little variation in the values, further explaining the good performance of the modified EC8 approach. It can be seen that the reduction of the flexural component is predicted to be significantly larger (mean of 0.66) than the reduction of the shear component (mean of 0.93). The statistics are listed in Table 6. However for practical applications it might be sufficient to use one value for both flexure and shear component of the stiffness in-between the above-mentioned such as the already mentioned 0.75 . 


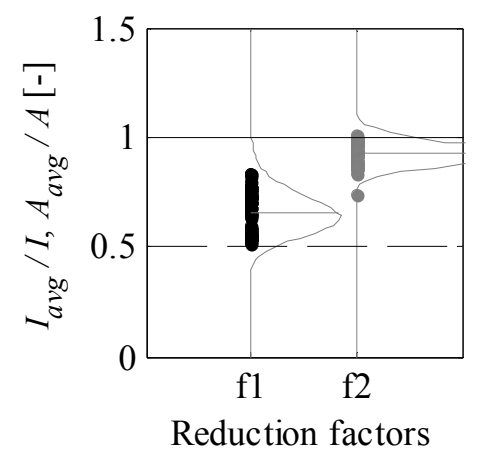

Figure 13: Distribution of stiffness reduction factors for flexural $\left(f_{1}\right)$ and shear $\left(f_{2}\right)$ component as determined with the simplified CDC model including corresponding lognormal probability distribution functions and indications of mean

Table 6: Statistics of stiffness reduction factor samples for wall tests according to simplified CDC model

\begin{tabular}{ccccc}
\hline Reduction factor & Mean & Median & Std. & CoV \\
\hline$f_{1}$ & 0.66 & 0.66 & 0.10 & 0.15 \\
$f_{2}$ & 0.93 & 0.94 & 0.05 & 0.06 \\
\hline
\end{tabular}

\section{$5 \quad$ Parametric studies on the ratio of effective-to-initial stiffness}

In the following parametric study, the simplified CDC model is used to investigate the influence of the shear span ratio $\left(H_{0} / L\right)$ and the axial load ratio $\left(\sigma_{0} / L\right)$ on the ratio of effective-to-initial stiffness of in-plane loaded URM walls. The parameters provided in Table 7 are used throughout the whole study; these are the wall thickness $T$, the brick height $h_{B}$, the brick length $l_{B}$, the friction coefficient $\mu$, the cohesion $c$, the compressive strength of masonry $f_{u}$, the compressive strength of a brick $f_{B, c}$ and the E-modulus of masonry $E$.

Table 7: Values used for all parametric studies, material parameters correspond to values obtained in [8]

\begin{tabular}{cccccccc}
\hline $\begin{array}{c}T \\
{[\mathrm{~mm}]}\end{array}$ & $\begin{array}{c}h_{B} \\
{[\mathrm{~mm}]}\end{array}$ & $\begin{array}{c}l_{B} \\
{[\mathrm{~mm}]}\end{array}$ & $\begin{array}{c}\mu \\
{[-]}\end{array}$ & $\begin{array}{c}c \\
{[\mathrm{MPa}]}\end{array}$ & $\begin{array}{c}f_{u} \\
{[\mathrm{MPa}]}\end{array}$ & $\begin{array}{c}f_{B, c} \\
{[\mathrm{MPa}]}\end{array}$ & $\begin{array}{c}E \\
{[\mathrm{MPa}]}\end{array}$ \\
\hline 200 & 190 & 300 & 0.94 & 0.27 & 5.86 & 35 & Eq. (4) clay \\
\hline
\end{tabular}

The influence of a change in shear span on the effective-to-initial stiffness ratio is presented in Figure 14a. The wall size is kept constant $(H=L=2.5 \mathrm{~m})$ while the shear span is increased. It can be seen that the effective-toinitial stiffness ratio shows a slight downward trend for increasing shear span. As already stressed in the previous sections, the predictions for the effective stiffness lie around 0.75 times the elastic stiffness, which is significantly higher than the provisions in EC8 Part 1 [17] and corresponds to the presented test results.

Figure $14 \mathrm{~b}$ further illustrates that the effective-to-initial stiffness ratio reduces slightly with increasing shear span ratio. For this plot, the wall height and shear span remain constant $\left(H=2.5 \mathrm{~m}, H_{0} / H=0.5,1.0\right)$ while the wall length is decreased. For walls with a lower shear span ratio (i.e. wall that are more likely to be shear controlled) there is a downward trend with increasing shear span ratio, a trend that appears to correspond to test results as shown in Sect. 2.2.2 and Figure 7e. The predictions vary again between 0.7 and 0.9 times the initial stiffness and are therefore in the vicinity of the empirically determined reduction factor of 0.75 . Subsequently the variation of the effective-to-initial stiffness ratio is investigated under increasing axial load ratio with a constant wall size and shear span $\left(H=L=2.5 \mathrm{~m}, H_{0} / H=0.5,1.5\right)$, Figure 14c. An upward trend with increasing axial load especially for walls with a higher shear span (that are therefore more likely to be flexure controlled) can be observed. This corresponds well to the finding that flexure controlled walls appear to show a slight upward trend in effective-toinitial stiffness ratio with increasing axial loading (see Sect. 2.2.2 and Figure 7c). Yet the values remain again in the vicinity of 0.75 times the elastic stiffness confirming the determined stiffness reduction factors. 
(a) $H=L=2.5 \mathrm{~m}$

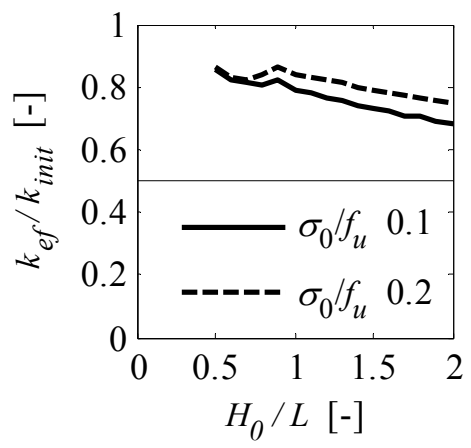

(b) $H=2.5 \mathrm{~m}, \sigma_{0} / f_{u}=0.1$

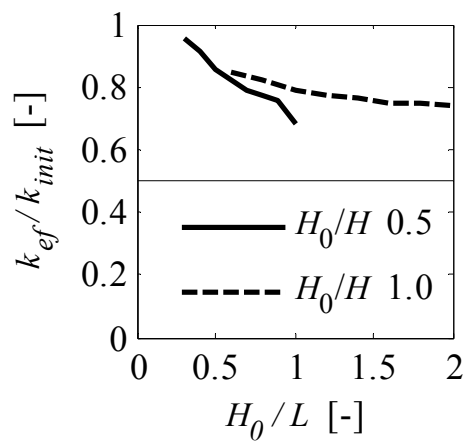

(c) $H=L=2.5 \mathrm{~m}$

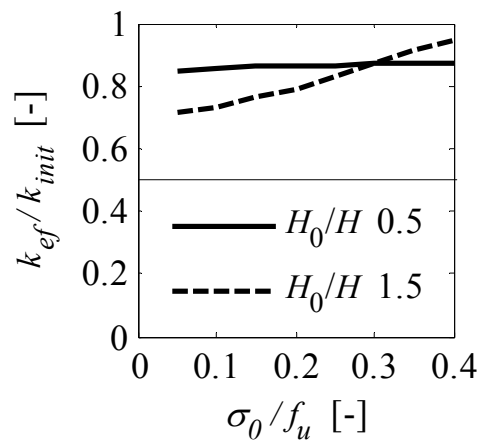

Figure 14: Parametric studies using CDCs model, ratio of effective-to-initial stiffness vs (a) shear span ratio, constant wall size; (b) shear span ratio, constant wall height, reducing wall length; (c) axial load ratio, constant wall size

\section{Conclusions}

This article treats the effective stiffness of in-plane loaded unreinforced masonry (URM) walls, which is defined herein as the secant stiffness of the wall at attainment of $70 \%$ of the peak shear capacity. The considered URM walls are made of masonry with regular clay, calcium silicate or aerated concrete block units. An investigation of experimental evidence from a data base of 79 full-scale shear-compression tests shows that both the initial and the effective stiffness appear to be positively dependent on the axial load ratio. In this paper, the effective stiffness is expressed as product of the initial stiffness and the ratio of effective to initial stiffness. Based on the test data, assuming that the Timoshenko beam model is applicable and that $G=0.25 E$, the initial masonry E-modulus can be estimated as follows:

$$
E\left(\sigma_{0}\right)=\alpha f_{u}\left(1+\beta \frac{\sigma_{0}}{f_{u}}\right)
$$

where $\alpha=470$ for clay brick and $\alpha=720$ for calcium silicate brick masonry walls with $\beta=4$ for both types. For other masonry typologies, the data base is insufficient for determining a typology-specific $\alpha$-value. This new expression for the E-modulus seems to yield less biased estimates of the measured initial stiffness than the provision in Eurocode 6 [36], which does not account for the dependency of the E-modulus on the axial load ratio but computes the E-modulus as a multiple of the compression strength $f_{u}$. The uncertainty related to the initial stiffness estimate remains, however, significant.

Furthermore, the experimental data shows that not only does the initial and effective stiffness depend on the axial load ratio but also the effective-to-initial stiffness ratio in flexure controlled walls shows a slight upward trend with the axial load ratio. In addition, the effective-to-initial stiffness ratio seems to show a downward trend with the shear span ratio for shear controlled walls. These observed trends are confirmed by an analytical model, which is put forward in this paper and validated against the experimental data.

The analytical model suggests that the reduction in stiffness is mainly caused by a reduction in flexural stiffness and to a lesser extent in shear stiffness. Moreover, the test data and the model indicate that the variation of the effective-to-initial stiffness ratio with the axial load and the shear span ratio is not that strong and may be approximated for practical purposes by a constant ratio of 0.75 . This ratio is, however, considerably higher than the value of 0.50 suggested in Eurocode 8 Part 1 [17]. Concluding, a comparison with experimental data shows that the scatter in the effective stiffness estimates may results to a large extent from the initial stiffness estimate and to a much smaller extent from errors in the determination of the effective-to-initial stiffness ratio.

\section{$7 \quad$ Acknowledgement}

This study has been supported by the grant no. 159882 of the Swiss National Science Foundation: "A drift capacity model for unreinforced masonry walls failing in shear".

\section{$8 \quad$ References}

1. D'Ayala DF. Force and displacement based vulnerability assessment for traditional buildings. Bulletin of 
Earthquake Engineering 2005; 3(3): 235-265. DOI: 10.1007/s10518-005-1239-x.

2. Lagomarsino S, Cattari S. PERPETUATE guidelines for seismic performance-based assessment of cultural heritage masonry structures. Bulletin of Earthquake Engineering 2015; 13(1): 13-47. DOI: 10.1007/s10518-014-9674-1.

3. Calvi GM. A displacement-based approach for vulnerability evaluation of classes of buildings. Journal of Earthquake Engineering 1999; 3(3): 411-438. DOI: 10.1080/13632469909350353.

4. Fajfar P. A Nonlinear Analysis Method for Performance-Based Seismic Design. Earthquake Spectra 2000; 16(3): 573-592. DOI: 10.1193/1.1586128.

5. Priestley MJN, Calvi GM, Kowalsky MJ. Displacement-based seismic design of structures. Pavia, Italy: IUSS Press; 2007.

6. Frumento S, Magenes G, Morandi P, Calvi GM. Interpretation of experimental shear tests on clay brick masonry walls and evaluation of q-factors for seismic design. Research Report EUCENTRE 2009/02, Pavia: IUSS Press; 2009. DOI: 10.13140/RG.2.2.13998.61766.

7. Gulkan P, Sozen MA. Inelastic Responses of Reinforced Concrete Structure to Earthquake Motions. ACI Journal Proceedings 1974; 71(12): 604-610. DOI: 10.14359/7110.

8. Petry S, Beyer K. Cyclic Test Data of Six Unreinforced Masonry Walls with Different Boundary Conditions. Earthquake Spectra 2015; 31(4): 2459-2484. DOI: 10.1193/101513EQS269.

9. Magenes G. A method for pushover analysis in seismic assessment of masonry buildings. Proceedings of the 12th World Conference on Earthquake Engineering, Auckland, New Zealand: 2000.

10. Lagomarsino S, Penna A, Galasco A, Cattari S. TREMURI program: An equivalent frame model for the nonlinear seismic analysis of masonry buildings. Eng Struct 2013; 56: 1787-1799. DOI: 10.1016/j.engstruct.2013.08.002.

11. Chen SY, Moon FL, Yi T. A macroelement for the nonlinear analysis of in-plane unreinforced masonry piers. Engineering Structures 2008; 30(8): 2242-2252. DOI: 10.1016/j.engstruct.2007.12.001.

12. Belmouden Y, Lestuzzi P. An equivalent frame model for seismic analysis of masonry and reinforced concrete buildings. Construction and Building Materials 2009; 23(1): 40-53. DOI: 10.1016/j.conbuildmat.2007.10.023.

13. Caliò I, Marletta M, Pantò B. A new discrete element model for the evaluation of the seismic behaviour of unreinforced masonry buildings. Engineering Structures 2012; 40(October 2015): 327-338. DOI: 10.1016/j.engstruct.2012.02.039.

14. Raka E, Spacone E, Sepe V, Camata G. Advanced frame element for seismic analysis of masonry structures: model formulation and validation. Earthquake Engineering \& Structural Dynamics 2015; 44(14): 2489-2506. DOI: 10.1002/eqe.2594.

15. Vanin F, Almeida JP, Beyer K. Force-based finite element for modelling the cyclic behaviour of unreinforced masonry piers. Proceedings of the 16th World Conference on Earthquake Engineering, Santiago, Chile: 2017.

16. Penna A, Lagomarsino S, Galasco A. A nonlinear macroelement model for the seismic analysis of masonry buildings. Earthquake Engineering \& Structural Dynamics 2014; 43(2): 159-179. DOI: 10.1002/eqe.2335.

17. CEN. EN 1998-1:2004 Eurocode 8: Design of structures for earthquake resistance - Part 1: General rules, seismic actions and rules for buildings. European Committee for Standardization, Brussels, Belgium, 2004.

18. Vanin F, Zaganelli D, Penna A, Beyer K. Estimates of the stiffness, strength and drift capacity of stone masonry walls based on 123 quasi-static cyclic tests reported in the literature. Bulletin of Earthquake Engineering 2017.

19. Salmanpour AH, Mojsilović N, Schwartz J. Displacement capacity of contemporary unreinforced masonry walls: An experimental study. Engineering Structures 2015; 89: 1-16. DOI: 10.1016/j.engstruct.2015.01.052.

20. CEN. EN 771-1+A1 Specification for masonry units - Part 1: Clay masonry units. European Committee for Standardization, Brussels, Belgium, 2015.

21. CEN. EN 771-2+A1 Specification for masonry units - Part 2: Calcium silicate masonry units. European Committee for Standardization, Brussels, Belgium, 2015.

22. CEN. EN 771-3+A1 Specification for masonry units - Part 3: Aggregate concrete masonry units (Dense 
and light-weight aggregates). European Committee for Standardization, Brussels, Belgium, 2015.

23. CEN. EN 771-4+A1 Specification for masonry units - Part 4: Autoclaved aerated concrete masonry units. European Committee for Standardization, Brussels, Belgium, 2015.

24. CEN. EN 1996-2 Eurocode 6: Design of masonry structures - Part 2: Design considerations, selection of materials and execution of masonry. European Committee for Standardization, Brussels, Belgium, 2006.

25. CEN. EN 998-2 Specification for mortar for masonry - Part 2: Masonry mortar. European Committee for Standardization, Brussels, Belgium, 2010.

26. Wilding BV, Beyer K. Force-displacement response of in-plane loaded unreinforced brick masonry walls: the Critical Diagonal Crack model. Bulletin of Earthquake Engineering 2017; 15(5): 2201-2244. DOI: 10.1007/s10518-016-0049-7.

27. Ganz H, Thürlimann B. Versuche an Mauerwerksscheiben unter Normalkraft und Querkraft. Test Report Nr. 7502-4, ETH Zürich: 1984.

28. Bosiljkov V, Tomaževič M, Lutman M. Optimization of shape of masonry units and technology of construction for earthquake resistant masonry buildings - Part One and Two. Research Report, ZAG Lubljana, Slowenia: 2004.

29. Bosiljkov V, Tomaževič M, Lutman M. Optimization of shape of masonry units and technology of construction for earthquake resistant masonry buildings - Part Three. Research Report, ZAG Lubljana, Slowenia: 2006.

30. Graziotti F, Rossi A, Mandirola M, Penna A, Magenes G. Experimental characterisation of calciumsilicate brick masonry for seismic assessment. Proceedings of the 16th International Brick and Block Masonry Conference, Padova, Italy: 2016.

31. Graziotti F, Tomassetti U, Rossi A, Marchesi B, Kallioras S, Mandirola M, et al. Shaking table tests on a full-scale clay-brick masonry house representative of the Groningen building stock and related characterization tests. Report EUC128/2016U, EUCENTRE, Pavia, Italy: 2016.

32. Messali F, Ravenshorst G, Esposito R, Rots J. Large-scale testing program for the seismic characterization of Dutch masonry walls. Proceedings of the 16th World Conference on Earthquake Engineering, Santiago, Chile: 2017.

33. Magenes G, Morandi P, Penna A. D 7.1c Test results on the behaviour of masonry under static cyclic in plane lateral loads. Test Report, ESECMaSE Poject, University of Pavia, EURCENTRE, Italy: 2008.

34. Ötes A, Löring S. Zum Tragverhalten von Mauerwerksbauten unter Erdbebenbelastung. Bautechnik 2006; 83(2): 125-138. DOI: 10.1002/bate.200610013.

35. Petry S, Beyer K. Force-displacement response of in-plane-loaded URM walls with a dominating flexural mode. Earthquake Engineering \& Structural Dynamics 2015; 44(14): 2551-2573. DOI: 10.1002/eqe.2597.

36. CEN. EN 1996-1-1:2005 Eurocode 6: Design of masonry structures - Part 1-1: General rules for reinforced and unreinforced masonry structures. European Committee for Standardization, Brussels, Belgium, 2005.

37. ASCE. ASCE 41-13: Seismic Evaluation and Retrofit of Existing Buildings. Reston, VA: American Society of Civil Engineers; 2014. DOI: 10.1061/9780784412855.

38. TMS. TMS 402: Building Code Requirements for Masonry Structures. The Masonry Society, Boulder, Colorado, 2008.

39. Tomaževič M. Shear resistance of masonry walls and Eurocode 6: shear versus tensile strength of masonry. Materials and Structures 2009; 42(7): 889-907. DOI: 10.1617/s11527-008-9430-6.

40. Derakhshan H, Griffith MC, Ingham JM. Airbag testing of multi-leaf unreinforced masonry walls subjected to one-way bending. Engineering Structures 2013; 57: 512-522. DOI: 10.1016/j.engstruct.2013.10.006.

41. CEN. EN 1052-1:1998-12 Methods of test for masonry - Part 1: Determination of compressive strength. European Committee for Standardization, Brussels, Belgium, 2002.

42. Sterne JAC. Sifting the evidence---what's wrong with significance tests? Another comment on the role of statistical methods. BMJ 2001; 322(7280): 226-231. DOI: 10.1136/bmj.322.7280.226.

43. Wasserstein RL, Lazar NA. The ASA's Statement on $\mathrm{p}$-Values: Context, Process, and Purpose. The American Statistician 2016; 70(2): 129-133. DOI: 10.1080/00031305.2016.1154108.

44. CEN. EN 1998-3:2005 Eurocode 8: Design of structures for earthquake resistance - Part 3: Assessment and retrofitting of buildings. European Committee for Standardization, Brussels, Belgium, 2005. 
45. Benedetti A, Steli E. Analytical models for shear-displacement curves of unreinforced and FRP reinforced masonry panels. Construction and Building Materials 2008; 22(3): 175-185. DOI: 10.1016/j.conbuildmat.2006.09.005.

\section{Appendix A}

Table 8 summarizes the main parameters of the tests used for comparison reasons in this article, where $L$ is the wall length, $T$ the wall thickness, $H$ the wall height, $H_{0} / H$ the ratio of shear span to wall height, $h_{B}$ the brick height, $l_{B}$ the brick length, $\sigma_{0}$ the axial stress, $f_{u}$ the mean masonry compressive strength, $E_{\text {init }}$ the initial elastic modulus.

Table 8: Wall parameters used in the comparison of model/tests

\begin{tabular}{|c|c|c|c|c|c|c|c|c|c|c|c|c|c|}
\hline Name & Ref. & Typ $^{1}$ & $\mathrm{Beh}^{2}$ & $\begin{array}{c}L \\
{[\mathrm{~mm}]}\end{array}$ & $\begin{array}{c}T \\
{[\mathrm{~mm}]}\end{array}$ & $\begin{array}{c}H \\
{[\mathrm{~mm}]}\end{array}$ & $\begin{array}{c}H_{0} / H \\
{[-]}\end{array}$ & $\begin{array}{c}h_{B} \\
{[\mathrm{~mm}]}\end{array}$ & $\begin{array}{c}l_{B} \\
{[\mathrm{~mm}]}\end{array}$ & $\begin{array}{c}\sigma_{0} \\
{[\mathrm{MPa}]}\end{array}$ & $\begin{array}{c}f_{u} \\
{[\mathrm{MPa}]}\end{array}$ & $\begin{array}{c}E_{\text {init }} \\
{[\mathrm{MPa}]}\end{array}$ & $\begin{array}{c}k_{e f}[\mathrm{kN} \\
/ \mathrm{mm}]\end{array}$ \\
\hline PUP1 & [8] & 1 & $\mathrm{~S}$ & 2010 & 200 & 2250 & 0.50 & 190 & 300 & 1.05 & 5.86 & 4196 & 96.2 \\
\hline PUP2 & [8] & 1 & $\mathrm{~S}$ & 2010 & 200 & 2250 & 0.75 & 190 & 300 & 1.05 & 5.86 & 3992 & 41.0 \\
\hline PUP3 & [8] & 1 & $\mathrm{~F}$ & 2010 & 200 & 2250 & 1.50 & 190 & 300 & 1.05 & 5.86 & 3741 & 37.9 \\
\hline PUP4 & [8] & 1 & $\mathrm{~F}$ & 2010 & 200 & 2250 & 1.50 & 190 & 300 & 1.54 & 5.86 & 4641 & 46.0 \\
\hline PUP5 & [8] & 1 & $\mathrm{~S}$ & 2010 & 200 & 2250 & 0.75 & 190 & 300 & 0.55 & 5.86 & 3243 & 44.7 \\
\hline PUP6 & [8] & 1 & $\mathrm{~S}$ & 2010 & 200 & 2250 & 1.05 & 190 & 300 & 1.05 & 5.86 & 3010 & 35.6 \\
\hline BNW1 & [29] & 1 & $\mathrm{~F}$ & 2567 & 297 & 1750 & 1.10 & 236 & 244 & 0.59 & 5.86 & 4425 & 213.2 \\
\hline BNW2 & [29] & 1 & $\mathrm{~S}$ & 2572 & 297 & 1753 & 1.10 & 236 & 244 & 1.19 & 5.86 & 6748 & 269.9 \\
\hline BNW3 & [29] & 1 & $\mathrm{~S}$ & 2584 & 297 & 1751 & 1.10 & 236 & 244 & 0.89 & 5.86 & 4105 & 160.7 \\
\hline BZW1 & [29] & 1 & $\mathrm{~S}$ & 2482 & 296 & 1750 & 1.10 & 237 & 244 & 0.95 & 5.86 & 4118 & 146.5 \\
\hline BZW2 & [29] & 1 & $\mathrm{~F}$ & 2484 & 296 & 1750 & 1.10 & 237 & 244 & 0.53 & 5.86 & 3683 & 164.6 \\
\hline BSW & [29] & 1 & $\mathrm{~S}$ & 2712 & 172 & 1820 & 1.10 & 188 & 288 & 2.07 & 5.86 & 6627 & 152.4 \\
\hline W1 & {$[27]$} & 1 & $\mathrm{~S}$ & 3600 & 150 & 2000 & 1.05 & 190 & 300 & 0.77 & 8.25 & 4153 & 136.7 \\
\hline W4 & [27] & 1 & $\mathrm{~F}$ & 3600 & 150 & 2000 & 2.00 & 190 & 300 & 0.78 & 8.25 & 5107 & 124.3 \\
\hline W6 & [27] & 1 & $\mathrm{~S}$ & 3600 & 150 & 2000 & 1.05 & 190 & 300 & 0.77 & 8.25 & 5252 & 175.5 \\
\hline W7 & [27] & 1 & $\mathrm{~S}$ & 3600 & 150 & 2000 & 1.05 & 190 & 300 & 2.39 & 8.25 & 6562 & 231.9 \\
\hline $\mathrm{P} 1$ & [19] & 1 & $\mathrm{~S}$ & 1500 & 150 & 1600 & 0.50 & 190 & 290 & 0.64 & 6.40 & 3209 & 66.7 \\
\hline $\mathrm{P} 2$ & [19] & 1 & $\mathrm{~S}$ & 1500 & 150 & 1600 & 0.50 & 190 & 290 & 0.96 & 6.40 & 4222 & 83.8 \\
\hline P3 & [19] & 4 & $\mathrm{~S}$ & 1500 & 150 & 1600 & 0.50 & 190 & 250 & 0.77 & 7.70 & 6481 & 121.5 \\
\hline P4 & [19] & 4 & $\mathrm{~S}$ & 1500 & 150 & 1600 & 0.50 & 190 & 250 & 1.16 & 7.70 & 7035 & 115.9 \\
\hline $\mathrm{T} 1$ & [19] & 1 & $\mathrm{~S}$ & 2700 & 150 & 2600 & 0.50 & 190 & 290 & 0.58 & 5.80 & 3677 & 73.7 \\
\hline $\mathrm{T} 2$ & [19] & 1 & $\mathrm{~S}$ & 2700 & 150 & 2600 & 0.50 & 190 & 290 & 0.29 & 5.80 & 3750 & 66.4 \\
\hline $\mathrm{T} 3$ & [19] & 1 & S & 2700 & 150 & 2600 & 0.50 & 190 & 290 & 1.16 & 5.80 & 4927 & 105.9 \\
\hline T6 & [19] & 1 & $\mathrm{~S}$ & 3600 & 150 & 2600 & 0.50 & 190 & 290 & 0.58 & 5.80 & 4894 & 142.1 \\
\hline $\mathrm{T} 7$ & [19] & 1 & $\mathrm{~F}$ & 2700 & 150 & 2600 & 1.00 & 190 & 290 & 0.58 & 5.80 & 4643 & 56.1 \\
\hline BNL1 & {$[28]$} & 1 & $\mathrm{~F}$ & 1028 & 300 & 1510 & 1.06 & 240 & 245 & 0.60 & 4.13 & 3445 & 49.5 \\
\hline BNL2 & [28] & 1 & F & 1030 & 300 & 1510 & 1.06 & 240 & 245 & 1.19 & 4.13 & 3912 & 47.1 \\
\hline BNL3 & [28] & 1 & $\mathrm{~F}$ & 1033 & 300 & 1515 & 1.06 & 240 & 245 & 0.60 & 4.13 & 3954 & 52.4 \\
\hline BNL4 & [28] & 1 & $\mathrm{~F}$ & 1025 & 300 & 1514 & 1.06 & 240 & 245 & 1.19 & 4.13 & 4839 & 60.7 \\
\hline BNL5 & [28] & 1 & $\mathrm{~F}$ & 1027 & 300 & 1511 & 1.06 & 240 & 245 & 1.19 & 4.13 & 4263 & 52.1 \\
\hline BNL6 & [28] & 1 & F & 1026 & 300 & 1508 & 1.06 & 240 & 245 & 0.60 & 4.13 & 3568 & 48.9 \\
\hline BGL1 & [28] & 1 & $\mathrm{~F}$ & 989 & 300 & 1513 & 1.06 & 237 & 245 & 1.19 & 4.31 & 4532 & 55.7 \\
\hline BGL2 & [28] & 1 & $\mathrm{~F}$ & 987 & 300 & 1511 & 1.06 & 237 & 245 & 1.19 & 4.31 & 3971 & 47.9 \\
\hline BPL1 & [28] & 1 & $\mathrm{~F}$ & 985 & 300 & 1508 & 1.06 & 236 & 245 & 1.19 & 6.28 & 6623 & 51.1 \\
\hline BPL2 & [28] & 1 & $\mathrm{~F}$ & 985 & 300 & 1509 & 1.06 & 236 & 245 & 1.19 & 6.28 & 6854 & 50.2 \\
\hline BPL3 & [28] & 1 & $\mathrm{~F}$ & 986 & 300 & 1507 & 1.06 & 236 & 245 & 1.19 & 6.28 & 5308 & 43.8 \\
\hline BZL1 & [28] & 1 & $\mathrm{~F}$ & 988 & 300 & 1510 & 1.06 & 235 & 243 & 1.19 & 6.24 & 6738 & 60.5 \\
\hline BZL2 & [28] & 1 & $\mathrm{~F}$ & 987 & 300 & 1512 & 1.06 & 235 & 243 & 1.19 & 6.24 & 5137 & 53.6 \\
\hline BZL3 & [28] & 1 & $\mathrm{~F}$ & 986 & 300 & 1508 & 1.06 & 235 & 243 & 1.19 & 6.24 & 7894 & 60.5 \\
\hline EC_Comp1 & {$[30]$} & 4 & $\mathrm{~F}$ & 1100 & 102 & 2750 & 0.50 & 71 & 212 & 0.52 & 6.20 & 6229 & 11.7 \\
\hline EC_Comp3 & {$[30]$} & 4 & $\mathrm{~S}$ & 4000 & 102 & 2750 & 1.00 & 71 & 212 & 0.30 & 6.20 & 6900 & 111.1 \\
\hline
\end{tabular}




\begin{tabular}{|c|c|c|c|c|c|c|c|c|c|c|c|c|c|}
\hline Name & Ref. & Typ $^{1}$ & $\mathrm{Beh}^{2}$ & $\begin{array}{c}L \\
{[\mathrm{~mm}]}\end{array}$ & $\begin{array}{c}T \\
{[\mathrm{~mm}]}\end{array}$ & $\begin{array}{c}H \\
{[\mathrm{~mm}]}\end{array}$ & $\begin{array}{c}H_{0} / H \\
{[-]}\end{array}$ & $\begin{array}{c}h_{B} \\
{[\mathrm{~mm}]}\end{array}$ & $\begin{array}{c}l_{B} \\
{[\mathrm{~mm}]}\end{array}$ & $\begin{array}{c}\sigma 0 \\
{[\mathrm{MPa}]}\end{array}$ & $\begin{array}{c}f_{u} \\
{[\mathrm{MPa}]}\end{array}$ & $\begin{array}{c}E_{\text {init }} \\
{[\mathrm{MPa}]}\end{array}$ & $\begin{array}{c}k_{e f}[\mathrm{kN} \\
/ \mathrm{mm}]\end{array}$ \\
\hline EC_Comp21 & {$[31]$} & 3 & $\mathrm{~F}$ & 1200 & 208 & 2710 & 0.50 & 50 & 208 & 0.52 & 11.22 & 7041 & 53.7 \\
\hline EC_Comp22 & {$[31]$} & 3 & $\mathrm{~F}$ & 1200 & 208 & 2710 & 0.50 & 50 & 208 & 1.20 & 11.22 & 7997 & 48.8 \\
\hline EC_Comp23 & [31] & 3 & $\mathrm{~F}$ & 1200 & 208 & 2710 & 0.50 & 50 & 208 & 0.86 & 11.22 & 7341 & 44.5 \\
\hline EC_Comp24 & {$[31]$} & 3 & $\mathrm{~S}$ & 2740 & 208 & 2710 & 0.50 & 50 & 208 & 0.30 & 11.22 & 8160 & 209.3 \\
\hline EC_Comp 25 & {$[31]$} & 3 & $\mathrm{~S}$ & 2740 & 208 & 2710 & 0.50 & 50 & 208 & 0.30 & 11.22 & 8921 & 175.8 \\
\hline Comp0 & {$[32]$} & 4 & $\mathrm{~F}$ & 1100 & 102 & 2760 & 0.50 & 71 & 210 & 0.70 & 5.90 & 7096 & 7.8 \\
\hline Comp1 & [32] & 4 & $\mathrm{~F}$ & 1100 & 102 & 2760 & 1.00 & 71 & 210 & 0.70 & 5.90 & 5163 & 4.3 \\
\hline Comp2 & [32] & 4 & $\mathrm{~F}$ & 1100 & 102 & 2760 & 1.00 & 71 & 210 & 0.50 & 5.90 & 5900 & 3.1 \\
\hline Comp3 & [32] & 4 & $\mathrm{~F}$ & 1100 & 102 & 2760 & 0.50 & 71 & 210 & 0.40 & 5.90 & 6005 & 12.6 \\
\hline Comp4 & [32] & 4 & S & 4000 & 102 & 2760 & 0.50 & 71 & 210 & 0.50 & 5.90 & 7959 & 222.6 \\
\hline Comp6 & [32] & 4 & $\mathrm{~S}$ & 4000 & 102 & 2760 & 1.00 & 71 & 210 & 0.50 & 5.90 & 5669 & 100.1 \\
\hline CL01 & [33] & 2 & $F$ & 1500 & 175 & 2500 & 0.50 & 249 & 373 & 0.31 & 5.90 & 4918 & 54.2 \\
\hline CL03 & [33] & 2 & $\mathrm{~F}$ & 1000 & 365 & 2500 & 0.50 & 249 & 247 & 0.14 & 5.90 & 3686 & 29.2 \\
\hline CL05 & [33] & 1 & S & 2500 & 300 & 2600 & 0.50 & 190 & 250 & 0.68 & 9.50 & 3300 & 113.7 \\
\hline CL06 & [33] & 1 & $\mathrm{~F}$ & 1250 & 300 & 2600 & 0.50 & 190 & 250 & 0.50 & 9.50 & 2827 & 39.5 \\
\hline CL07 & [33] & 1 & $\mathrm{~S}$ & 1250 & 300 & 2600 & 0.50 & 190 & 250 & 0.50 & 6.60 & 1756 & 22.4 \\
\hline CL08 & [33] & 1 & $\mathrm{~S}$ & 2500 & 300 & 2600 & 0.50 & 190 & 250 & 0.68 & 6.60 & 1940 & 73.6 \\
\hline CL09 & [33] & 2 & S & 1250 & 300 & 2600 & 0.50 & 230 & 250 & 0.50 & 5.30 & 1994 & 23.4 \\
\hline CL10 & [33] & 2 & $\mathrm{~S}$ & 2500 & 300 & 2600 & 0.50 & 230 & 250 & 0.68 & 5.30 & 2262 & 68.6 \\
\hline CS01 & [33] & 5 & $\mathrm{~S}$ & 1250 & 175 & 2500 & 0.50 & 248 & 248 & 1.00 & 5.90 & 6844 & 41.9 \\
\hline $\mathrm{CS} 02$ & [33] & 5 & $\mathrm{~S}$ & 1250 & 175 & 2500 & 0.50 & 248 & 248 & 1.00 & 5.90 & 7894 & 51.2 \\
\hline $\mathrm{CS} 03$ & [33] & 5 & F & 1250 & 175 & 2500 & 0.50 & 248 & 248 & 0.50 & 5.90 & 7961 & 71.0 \\
\hline CS04 & [33] & 5 & $\mathrm{~S}$ & 1250 & 175 & 2500 & 0.50 & 248 & 248 & 2.00 & 5.90 & 8377 & 60.8 \\
\hline CS05 & [33] & 5 & $\mathrm{~F}$ & 1250 & 175 & 2500 & 0.50 & 248 & 248 & 1.00 & 5.90 & 11859 & 71.5 \\
\hline CS06 & [33] & 5 & F & 1250 & 175 & 2500 & 1.00 & 248 & 248 & 1.00 & 5.90 & 9058 & 28.2 \\
\hline $\mathrm{CS} 07$ & [33] & 5 & F & 2500 & 175 & 2500 & 0.50 & 248 & 248 & 1.00 & 5.90 & 7771 & 145.8 \\
\hline CS08 & [33] & 5 & $\mathrm{~F}$ & 2500 & 175 & 2500 & 1.00 & 248 & 248 & 1.00 & 5.90 & 5415 & 69.2 \\
\hline CS09 & [33] & 5 & $\mathrm{~S}$ & 1250 & 175 & 2500 & 0.50 & 498 & 498 & 1.00 & 5.90 & 7506 & 60.3 \\
\hline V1 & [34] & 5 & $\mathrm{~S}$ & 2500 & 175 & 2500 & 1.00 & 248 & 498 & 0.50 & 15.00 & 6449 & 90.1 \\
\hline V3 & [34] & 6 & $\mathrm{~S}$ & 1250 & 300 & 2500 & 0.50 & 248 & 498 & 0.32 & 11.40 & 1839 & 19.7 \\
\hline V4 & [34] & 5 & $\mathrm{~F}$ & 1250 & 175 & 2500 & 0.50 & 248 & 498 & 0.67 & 15.00 & 5701 & 25.5 \\
\hline V5 & [34] & 6 & $\mathrm{~S}$ & 1250 & 300 & 2500 & 0.50 & 238 & 498 & 0.39 & 2.00 & 1693 & 20.2 \\
\hline V6 & [34] & 1 & $\mathrm{~F}$ & 1250 & 175 & 2500 & 0.50 & 238 & 498 & 0.55 & 5.60 & 4095 & 30.4 \\
\hline V7 & [34] & 5 & $\mathrm{~S}$ & 2500 & 175 & 2500 & 0.60 & 248 & 498 & 0.51 & 15.00 & 8868 & 143.5 \\
\hline V8 & [34] & 1 & $\mathrm{~S}$ & 2500 & 175 & 2500 & 0.60 & 238 & 498 & 0.51 & 5.60 & 3948 & 82.0 \\
\hline V9 & [34] & 6 & $\mathrm{~S}$ & 2500 & 175 & 2500 & 0.60 & 238 & 373 & 0.51 & 2.30 & 7823 & 174.2 \\
\hline V10 & [34] & 6 & $\mathrm{~S}$ & 2500 & 300 & 2500 & 0.60 & 249 & 498 & 0.30 & 11.40 & 1450 & 59.5 \\
\hline V11 & [34] & 1 & $\mathrm{~S}$ & 2500 & 175 & 2500 & 1.00 & 238 & 498 & 0.51 & 5.60 & 3355 & 49.4 \\
\hline
\end{tabular}

1) Masonry typology as explained in Table 1

2) The shear force-displacement behaviour corresponds to the one reported in the reference document. If the behaviour was reported as 'hybrid' or 'doubtful', it was assigned to F or S based on the shape of the final cycles of the shear force-drift hysteresis, F: flexure controlled, S: shear controlled

\section{Appendix B}

The procedure used to determine the initial stiffness $k_{\text {init }}$ of the considered URM shear-compression tests is outlined here. The following issues in the determination of the wall initial stiffness were identified: (i) the test results are often not available in digital format but only as pixel-graphics images which complicates the proper identification the initial force-displacement loops and the digitalization of the force-displacement response; (ii) as a result, the discretization of the resulting digitalized force-displacement responses may be rather low; (iii) the initial stiffness in both loading directions might be different; (iv) the reported measurements might refer to different heights (e.g. mid-height of loading beam, top of the wall); (v) at times it may be questionable if the reported shear-force-drift hysteresis really corresponds to the provided boundary conditions. 
Problems (i)-(ii) were approached by digitalizing the available non-digital data as thoroughly as possible and only using the envelope of the force-displacement hysteresis in the analyses. The initial stiffness per loading direction is therefore usually determined by the first data point of the envelope (after the initial $V=u=0$ of course). Issue (iii) was handled by averaging the initial stiffness of both loading directions to account for an un-symmetric forcedisplacement hysteresis and problem (v) was dealt with by introducing a quality criterion, representing the shear force capacity of a wall against overturning: $V=N L /\left(2 \mathrm{H}_{0}\right)$. If the reported shear force capacity were higher than this limit state, it could be inferred that the reported boundary conditions did not correspond to the reported forcedisplacement behaviour. With regard to issue (iv), little can be done but assuming that the researchers conducting the tests had measured the displacement on the wall top as precisely and thoroughly as possible.

The outlined procedure could be checked as Salmanpour et al. [19] reported the initial stiffness measured in their tests. These were compared to the ones determined according to the above-described procedure and a good agreement could be observed (mean reported/determined of 1.04 with a standard deviation of 0.12 ). 